$10 \Lambda$ nueva época

REALA, n 3, enero-junio 2015 ISSN: 1989-8975

DOI: http://dx.doi.org/10.24965/reala.voi3.10239

\title{
El consorcio administrativo en la encrucijada'
}

Francisco Toscano Gil

Profesor Contratado Doctor de Derecho Administrativo. Universidad Pablo de Olavide de Sevilla

ftosgil@upo.es

\section{Resumen}

Este trabajo tiene por objeto analizar las novedades introducidas en el régimen legal de los consorcios administrativos por las leyes $27 / 2013$ y 15/2014, que han modificado la regulación previa que se establecía en las leyes 7/1985 y 30/1992. Se analizan las soluciones y problemas que plantean estas dos leyes, para determinar si, tras la encrucijada en que la reforma ha situado a esta clásica institución, el consorcio administrativo ha encontrado su final, o, por el contrario, simplemente ha sido redimensionado.

\section{Palabras clave}

Consorcio administrativo, consorcio local, Administración pública, reforma local.

\section{The administrative consortium at the crossroads}

\section{Abstract}

This paper analyzes the new legal regime of administrative consortia introduced by law 27/2013 and law 15/2014, which have changed the laws $7 / 1985$ and 30/1992. Solutions and problems posed by these two laws are studied in order to determine whether, after the reform, the consortium will disappear, or, conversely, only will be resized.

\section{Keywords}

Administrative consortium, local consortium, public administration, local reform.

1 Este trabajo se ha realizado en el marco del proyecto de investigación del Ministerio de Economía y Competitividad, Plan Nacional de I+D+i, “Público y privado en la reordenación de las competencias locales” (DER2012-39216-C02-01), cuyo investigador principal es el Dr. Alfredo Galán Galán. 
I. Introducción. II. Concepto, caracteres y regulación del consorcio administrativo. 1. Concepto, características y regulación del consorcio administrativo. 2. Regulación. 3. Polémica sobre su naturaleza jurídica. III. Novedades de la LERSAL. 1. Objetivo de la reforma. 2. La adscripción del consorcio. 3. El personal del consorcio. 4. Limitaciones a la constitución de nuevos consorcios. 5. Limitaciones derivadas de la Disposición adicional $9^{\text {a }}$ LBRL: redimensionamiento del sector público local. 6. Limitaciones al número máximo de los miembros de los órganos de gobierno del consorcio y a la existencia y retribuciones del personal directivo. IV. Novedades de la Ley 15/2014. 1. Cuestiones preliminares. 2. La separación de los miembros del consorcio: causas, procedimiento y efectos. 3. La disolución del consorcio. V. Conclusiones. VI. Bibliografía.

\section{INTRODUCCIÓN}

A estas alturas resulta ya un lugar común afirmar que entre los efectos de la larga crisis económica que nos viene asolando en los últimos años, se encuentra el replanteamiento del tamaño del Estado, entendido como posible solución a la misma, por la vía de su adelgazamiento. Se entiende que el aparato de éste, al que se ha acusado de sobredimensionado, ha sido parte del problema, por ineficiente e insostenible, acompañado de un elevado nivel de deuda pública, que ha contribuido, en gran medida, a que ésta haya sido, fundamentalmente, una crisis de endeudamiento del sistema.

Bajo este planteamiento, se pone la mirada en el sector público, en el conjunto de organizaciones de las Administraciones Públicas, con especial atención a lo que se conoce como el sector público instrumental, esto es, la red de personificaciones, públicas o privadas, vinculadas o dependientes de las Administraciones Públicas territoriales ${ }^{2}$.

Por esta razón, los primeros planes de reforma de la Administración Pública planteados por el Gobierno de España durante la presente legislatura han tenido por objeto la reducción del sector público instrumental estatal. En un primer momento de forma más tímida3 , de forma más contundente en las últimas medidas adoptadas4. Pero sin que, en ningún caso, se haya abordado todavía una verdadera reforma del régimen jurídico de la Administración Pública, que la haga más eficaz y eficiente. Tan solo hasta ahora un adelgazamiento de su estructura organizativa, disfrazado de redimensionamiento o racionalización del sector público instrumental, eufemismo que encubre la reducción de éste, pero sin atender todavía al músculo de la Administración Pública, para convertirla en eso que se dice que se quiere y se necesita, una Administración del siglo XXI, capaz de responder a los retos de la sociedad. Con todo, hay que decir que, para el futuro, ya se ha anunciado una nueva ley de procedimiento administrativo común, así como una ley de régimen jurídico de las Administraciones Públicas, con las que el Gobierno de la Nación pretende culminar la legislatura en su último tramo 5 .

La incidencia sobre el sector público instrumental no estatal, ha venido de la mano de algunas normas que, dictadas en el ejercicio de competencias estatales, han tenido una repercusión directa sobre éste. En primer lugar, obvio es decirlo, la Ley Orgánica 2/2012, de 27 de abril, de Estabilidad Presupuestaria y Sostenibilidad Financiera (en adelante LOEPSF), pero también, de forma más específica, en lo que interesa al objeto de este trabajo, afectando al sector público local, la Ley 27/2013, de 27 de diciembre, de racionalización y sostenibilidad de la Administración Local (en adelante LERSAL). Por el contrario, la más reciente Ley 15/2014, de 16 de septiembre, de racionalización del Sector Público y otras medidas de reforma administrativa (en adelante Ley 15/2014), vuelve a incidir, fundamentalmente, sobre el sector público estatal, aunque contiene algunas disposiciones relativas a los consorcios que lo trascienden, y que van a ser objeto de nuestra atención.

Entre las entidades que conforman el sector público instrumental, una de las que ha sido objeto de mayores recelos ha sido el consorcio administrativo, que por su peculiar naturaleza jurídica ha resultado siempre difícil de

2 En este punto debe citarse el análisis que se hizo de las primeras medidas adoptadas en MONTOYA MARTíN, E. (2012). Para un análisis más reciente de la misma autora, centrado en el sector público local, véase MONTOYA MARTíN, E. (2014).

3 Nos referimos al Plan de reestructuración y racionalización del sector público empresarial y fundacional estatal, aprobado por Acuerdo del Consejo de Ministros de 16 de marzo de 2012.

4 Estamos hablando de las medidas puestas en marcha con la constitución, mediante Acuerdo del Consejo de Ministros de 26 de octubre de 2012, de la Comisión para la reforma de las Administraciones Públicas (CORA), siendo la última la aprobación de la Ley 15/2014, de 16 de septiembre, de racionalización del Sector Público y otras medidas de reforma administrativa.

5 En el momento en que se cierra este trabajo se conocen ya los textos de los dos anteproyectos de ley: Ley del procedimiento administrativo común de las Administraciones Públicas y Ley de régimen jurídico del sector público (en adelante, este último será citado como LRJSP). Ambos han sido sometido a un trámite de información pública que finalizó el pasado 6 de febrero. 
aprehender por los distintos operadores jurídicos. Por ello, la reforma del régimen jurídico de los consorcios, que constituye el tema de nuestro estudio, responde al objetivo de clarificar su régimen jurídico, para así hacerlo más aprehensible y controlable, desde la perspectiva económico-financiera, que es la que preocupa al legislador. Y, al mismo tiempo, en aplicación de ese control, se busca el redimensionamiento o racionalización de la utilización de esta figura en el conjunto del sector público, léase, su reducción, con el fin de disminuir el montante total del gasto público.

Esta reforma del régimen de los consorcios se ha llevado a cabo mediante normas dictadas en el ejercicio de la competencia del Estado para establecer las bases del régimen jurídico de las Administraciones Públicas (art. 149.1.18 $\mathrm{CE})^{6}$, en cuanto el consorcio administrativo es Administración. Pero con un distinto nivel de incidencia sobre las distintas Administraciones que pueden constituir consorcios. Así, por un lado y en una primera fase, se ha abordado mediante la LERSAL, que contiene algunas disposiciones aplicables, en principio, a todos los consorcios administrativos, para lo cual se reforma la Ley 30/1992, de 26 de noviembre, de Régimen Jurídico de las Administraciones Públicas y del Procedimiento Administrativo Común (en adelante LRJPAC). Pero también, como no podía ser de otra manera, dado el nombre de la Ley, recoge preceptos específicos para los consorcios locales, modificando la Ley $7 / 1985$, de 2 de abril, reguladora de las Bases del Régimen Local (en adelante LBRL). En una segunda fase, más reciente, se han innovado las reglas de los consorcios mediante las disposiciones recogidas en los artículos 12-15 de la Ley 15/2014, que son de aplicación a todas las Administraciones Públicas.

El objeto de este trabajo, ya se ha dicho, es el análisis de la reforma de los consorcios efectuada por ambas leyes, valorando las soluciones y problemas que éstas plantean, y, a fin de determinar si, tras la encrucijada en que la modificación normativa ha situado a esta clásica institución, el consorcio administrativo ha encontrado su final, o, por el contrario, del proceso de adaptación de sus estatutos al que ésta obliga, resultará un consorcio distinto, redimensionado, pero no por ello menos útil a la sociedad y a los intereses generales a los que debe servir.

\section{CONCEPTO, CARACTERÍSTICAS Y REGULACIÓN DEL CONSORCIO ADMINISTRATIVO}

No resulta posible ni oportuno en estas páginas detenerse a realizar un estudio en profundidad del consorcio administrativo, institución sobradamente conocida por todos, y dotada de un acervo doctrinal consistente y actualizado ${ }^{7}$. Pero sí es necesario entrar a definir brevemente sus notas caracterizadoras, referirse a las normas donde se encuentra su regulación, y apuntar sucintamente el problema de su naturaleza jurídica. Y ello tanto para entender mejor lo que se expondrá a continuación, cuando se aborden las novedades introducidas por la reforma, como en la medida en que de ésta pudiera resultar una alteración significativa de lo que hasta ahora sabíamos del consorcio.

\section{Concepto y características de los consorcios administrativos}

Un consorcio administrativo es una Administración Pública instrumental de base asociativa. Como Administración Pública es un ente dotado de personalidad jurídico-pública, que ejerce potestades administrativas y se rige por el Derecho Administrativo ${ }^{8}$. En tanto entidad instrumental de base asociativa, el consorcio se caracteriza por depender de un ente matriz, en realidad una pluralidad de entes matrices, en la medida en que lo integran, asociándose para ello, diversas Administraciones Públicas, e incluso, en su caso, entidades privadas sin ánimo de lucro en identidad de fines con las Administraciones con las que se asocian?. De lo que resulta que esta base asociativa puede calificarse de heterogénea, en cuanto las Administraciones que lo componen no tienen que ser necesariamente del mismo tipo ${ }^{10}$, además de admitir en su seno, como se acaba de decir, entidades que no son Administraciones Públicas. A su vez, la naturaleza asociativa del consorcio implica su voluntariedad, siendo así que las entidades que lo integran lo hacen voluntariamente, no porque se les imponga desde un nivel de gobierno superior.

Esta base asociativa lo diferencia de otras entidades instrumentales públicas, como los organismos autónomos, mientras que la heterogeneidad en su composición lo distingue de otras fórmulas asociativas de

6 Si bien, para la parte de la reforma llevada a cabo por la LERSAL, la Disposición final $5^{\text {a }}$ de ésta también invoca como título competencial el art. 149.14 CE (Hacienda general y deuda del Estado), como fundamento de toda la Ley, junto con el art. 149.1.18 , sin mayor precisión. Al respecto, véase el análisis de VELASCO CABALLERO, F. (2014).

7 Los referentes clásicos son los trabajos de MARTíN MATEO, R. (1970), MARTíN MATEO, R. (1987) y MARTíNEZ LÓPEZ-MUÑIZ, J.L. (1974). Este acervo doctrinal ha sido actualizado en las obras más recientes de NIETO GARRIDO, E. (1997) y TOSCANO GIL, F. (2011b).

8 En este mismo sentido, puede verse CASTILLO BLANCO, F. (2001): 118 y REBOLLO PUIG, M. (1997): 251.

9 La pluralidad de entidades matrices ha sido subrayada por REBOLLO PUIG, M. (1997): 203-205.

10 Véanse al respecto las reflexiones de LÓPEZ MENUDO, F. (1995): 23 y 24. 
naturaleza jurídico-pública, como la mancomunidad de municipios"1" siendo dicha personalidad jurídico-pública lo que lo separa de otras formas de gestión compartida, como las sociedades mercantiles participadas por diversas Administraciones Públicas, que ni pueden ejercer potestades públicas ni se rigen por el Derecho Administrativo.

De otra parte, el consorcio administrativo se concibe como una técnica organizativa de cooperación interadministrativa, dentro del catálogo de los diversos instrumentos de relaciones interadministrativas establecido por nuestro ordenamiento. La cooperación, que se lleva a cabo entre iguales, de forma voluntaria, a diferencia de la coordinación obligatoria, tiene por finalidad la puesta en común de asuntos del interés de las entidades consorciadas, siendo posible la gestión de fines plurales, sin que el consorcio tenga que ser una entidad monofuncional ${ }^{12}$. El dotarse de una estructura organizativa propia para el logro de estos fines lo diferencia de otra técnica de cooperación interadministrativa, como el convenio, al que tendremos ocasión de referirnos más adelante por relación al consorcio, y que no exige creación de organización nueva alguna.

\section{Regulación}

La primera regulación del consorcio administrativo, con la configuración más próxima a la que conocemos hoy, se lleva a cabo en el nivel local por el aún vigente Decreto de 17 de junio de 1955, por el que se aprueba el Reglamento de Servicios de las Corporaciones Locales (en adelante RSCL), arts. 37-40. A éste le seguiría, ya tras la promulgación de la Constitución Española de 1978, la LBRL de 1985 (arts. 57 y 87) y el Real Decreto Legislativo 781/1986, de 18 de abril, por el que se aprueba el Texto Refundido de las disposiciones legales vigentes en materia de Régimen Local (en adelante TRRL), art. 110. La principal novedad de esta nueva regulación postconstitucional fue la posibilidad de incorporar al consorcio entidades privadas sin ánimo de lucro, en concurrencia de intereses con las Administraciones Públicas, opción que no estaba en la norma de 1955.

Con la LRJPAC en el año 1992 se produce lo que la doctrina ha dado en llamar la deslocalización del consorcio ${ }^{13}$ (art. 6.5 en la redacción vigente ${ }^{14}$ ), fenómeno con el que quiere aludirse a la extensión de la utilización del consorcio más allá del mundo local, de tal modo que ya no se trate necesariamente de consorcios locales, sino, en general, de consorcios administrativos, que podrán ser locales, pero también estatales o autonómicos, según la órbita del ordenamiento jurídico en el que se sitúen ${ }^{15}$. Este precepto de la Ley del año 1992 ha de acompañarse en la actualidad de la nueva Disposición adicional $20^{\text {a }}$ de la LRJPAC introducida en el 2013 por la LERSAL, además de los arts. 12 a 15 contenidos en la Ley 15/2014, por cuanto todos ellos conforman un corpus de normativa estatal básica aplicable, en principio, a todo tipo de consorcios administrativos, al margen del ordenamiento territorial de procedencia de los mismos ${ }^{16}$. Más adelante habrá ocasión de comentar detalladamente estos nuevos preceptos.

Toda esta normativa estatal, al menos la que se entienda que es normativa básica, ha de ser completada con la correspondiente legislación autonómica de desarrollo, tanto la que prevé la creación de consorcios por la Administración autonómica ${ }^{17}$ como la que regula su constitución por las entidades locales de una Comunidad Autónoma ${ }^{18}$. Y, finalmente, para tener la visión completa de lo que constituye el Derecho propio del consorcio, hay que estar a lo que dispongan sus estatutos, norma autónoma aprobada por las entidades consorciadas, que particulariza el régimen jurídico de éste, pero sin que puedan contradecir lo dispuesto en la ley ${ }^{19}$.

\section{Polémica sobre su naturaleza jurídica}

No podemos cerrar este epígrafe sin dar noticia, aunque sea brevemente, de la conocida polémica sobre la naturaleza jurídica del consorcio, dado que, como se verá en las páginas que siguen, se trata de una cuestión que ha recobrado importancia con la reforma. Como ya apuntábamos al principio, el problema de la naturaleza

11 Lo que ha sido destacado por BARRERO RODRÍGUEZ, C. (2002): 84.

12 Hemos llamado la atención sobre esta cuestión en TOSCANO GIL, F. (2011b): 83-85.

13 Ver NIETO GARRIDO, E. (1997): 62 y TOSCANO GIL, F. (2011b): 34.

14 Art. 7 de la LRJPAC en su redacción originaria.

15 En puridad, la deslocalización del consorcio tuvo lugar unos años antes, mediante ley catalana 13/1989, de 14 de diciembre, de organización, procedimiento y régimen jurídico de la Administración de la Generalidad de Cataluña (art. 55).

16 Debe apuntarse que el anteproyecto de LRJSP prevé la integración de toda esta regulación estatal, incluyendo la recogida en la LBRL y en el TRRL, en una única norma, el citado anteproyecto de ley, cuyos artículos 93 a 102 establecen una regulación completa de esta figura. Ello pasará por la derogación de los preceptos correspondientes de la LRJPAC, LBRL, TRRL y Ley $15 / 2014$.

17 Al respecto, véase el trabajo de FERREIRA FERNÁNDEZ, A.J. (2009).

18 Sin ánimo exhaustivo, a título de ejemplo, en la Comunidad Autónoma de Andalucía, sería representativo de lo primero el art. 12 de la Ley 9/2007, de 22 de octubre, de la Administración de la Junta de Andalucía, y de lo segundo los arts. 78 y ss. de la Ley 5/2010, de 11 de junio, de autonomía local de Andalucía.

19 En este mismo sentido, puede verse CASTILLO BLANCO, F. (1991): 409, ESCRIBANO COLLADO, P. (2002): 111, NIETO GARRIDO, E. (1997): 107 y 108, y MARTÍN MATEO, R. (1987): 120. 
jurídica del consorcio viene dado por la diversidad de Administraciones Públicas, incluso entidades que no son Administración, que pueden formar parte del mismo. Aun estando pacíficamente aceptado que el consorcio administrativo es una Administración Pública, con todo lo que ello implica, el hecho de tratarse de una entidad compuesta por entes de diverso tipo arroja la duda acerca de qué tipo de entidad sea. Dicho de manera cruda, en ocasiones, no se ha sabido entender bien qué es un consorcio.

Esto tiene consecuencias importantes a la hora de determinar su régimen jurídico, no teniéndose claro en qué casos se aplica el ordenamiento jurídico estatal, o un determinado ordenamiento jurídico autonómico o local. Pese que, como se ha afirmado acertadamente, esta cuestión ya no tiene hoy tanta relevancia habida cuenta de la homogeneización del régimen jurídico de nuestras Administraciones Públicas ${ }^{20}$, también es cierto que siguen existiendo normas específicas de cada círculo territorial del ordenamiento jurídico que difieren en función de éste. $\mathrm{Y}$, sobre todo, preocupa, y más en estos últimos años, la sujeción a un ordenamiento jurídico concreto desde la perspectiva del control económico-financiero y presupuestario. Para poder sujetar a control al consorcio, primero hay que saber qué es.

No obstante, aunque este último es el contexto en que recobra fuerza la cuestión de su naturaleza jurídica, a fin de poder aprehender al consorcio y someterlo a medidas de control, el problema viene de lejos, no por esta última razón, sino ligado a la configuración del consorcio en el mundo local. Es fundamentalmente en el año 1985 , con la aprobación de la LBRL, cuando la polémica adquiere carta de naturaleza, y recordemos que, en ese año, aún no se había producido la llamada deslocalización del consorcio. Habiendo sido hasta entonces un lugar común la consideración del consorcio local como entidad local, esto es, persona jurídico-pública, Administración, sujeta al ordenamiento jurídico local, la no inclusión del consorcio entre las entidades locales listadas en el art. 3 LBRL hace saltar por los aires el consenso que existía sobre esta afirmación.

No vamos a reproducir aquí los términos de esta polémica, que ya ha sido bien expuesta en otras obras ${ }^{21}$, lo que toca ahora es dejar constancia de la forma en que se resolvió, con una conocida Sentencia del Tribunal Supremo, de 30 de abril de 1999. Esta sentencia vino a decir que si el legislador no había establecido expresamente que el consorcio local era una entidad local, ello era porque la diversidad de entidades que podían formar parte del mismo conducía a que, realmente, la naturaleza jurídica del consorcio administrativo dependiera del caso. Por tanto, según esta sentencia, había que estar al análisis de los estatutos de cada consorcio para determinar si estábamos o no ante una entidad local, o bien ante una entidad de otro tipo, estatal o autonómica. Para ello, llamaba a estudiar criterios como el control efectivo de los órganos de gobierno del consorcio, o la participación mayoritaria en el mismo, de tal modo que sería este control del consorcio por las entidades de una determinada esfera territorial, lo que determinaría su naturaleza jurídica, estatal, autonómica o local, en función de quién controlara el consorcio 22 .

A esta sentencia le seguirían otras, en la misma línea ${ }^{23}$, pero también los parlamentos de algunas Comunidades Autónomas, que optaron por positivizar estos criterios, fundamentalmente en sus leyes de régimen local, determinando cuándo un consorcio había de considerarse entidad local ${ }^{24}$, pero también en las leyes de su Administración propia, a fin de fijar cuándo era parte del sector público de una determinada Comunidad Autónoma $^{25}$. En ambos casos, la ubicación del consorcio en el sector público local o autonómico tenía como consecuencia su sujeción a uno u otro ordenamiento jurídico a todos los efectos. Aunque el legislador estatal también sentó criterios, lo hizo desde la óptica de la legislación presupuestaria, pensando exclusivamente en la sujeción del consorcio a la misma ${ }^{26}$. Lo que no hubo fue una respuesta por parte del legislador estatal básico, uniforme y común para todas las Administraciones Públicas, y que se despegara de la perspectiva presupuestaria, entendiéndose entregada la decisión última acerca de la naturaleza jurídica del consorcio, y del Derecho aplicable al mismo, a la potestad de autoorganización de cada Comunidad Autónoma. La reforma llevada a cabo por la LERSAL ha incidido sobre esta cuestión, siendo ésta la razón por la que nos hemos detenido ahora a dar cuenta, aunque haya sido someramente, de la existencia de esta polémica. El problema, como tendremos ocasión de analizar más adelante, es que la LERSAL no lo ha hecho con claridad.

20 Así lo ha afirmado COSCULLUELA MONTANER, L. (2008): 308.

21 Por nuestra parte, puede verse TOSCANO GIL, F. (2011b): 38 y ss. También deben citarse aquí las obras de NIETO GARRIDO, E. (1997): 56 y ss., y MARTÍN MATEO, R. (1987): 112 y ss.

22 Un análisis de esta sentencia, de obligada referencia, es el que se hace en NIETO GARRIDO, E. (2001).

23 Nos remitimos al completo análisis jurisprudencial que se lleva a cabo en KONINCKX FRASQUET, A. (2014): 574-577.

24 Nos referimos a la Ley 5/1997, de 22 de julio, de Administración Local de Galicia, la Ley 20/2006, de 15 de diciembre, municipal y de régimen local de las Illes Balears, y la Ley 5/2010, de 11 de junio, de Autonomía Local de Andalucía. Este tema lo hemos analizado en TOSCANO GIL, F. (2011a). Específicamente, sobre la ley andaluza, puede verse TOSCANO GIL, F. (2010) y TOSCANO GIL, F. (2012).

25 Para esta cuestión, nos remitimos al trabajo de FERREIRA FERNÁNDEZ, A.J. (2009).

26 Véase sobre este tema el análisis de KONINCKX FRASQUET, A. (2014): 580 y 581. 


\section{NOVEDADES DE LA LERSAL}

Como ya se ha dicho, la reforma del régimen jurídico establecido por el Estado para los consorcios administrativos se ha producido en dos fases. Es la primera, que ha tenido lugar a finales del año 2013 mediante la LERSAL, la que vamos a analizar en este apartado. Sin duda, se trata de la más importante, tanto por su extensión como por el alcance de sus previsiones. Por un lado, en la medida en que reforma la LRJPAC, estableciendo disposiciones aplicables, en principio, a todos los consorcios administrativos, y con las que comenzaremos nuestro estudio. Pero también porque incide de forma específica sobre los consorcios locales, en la manera en que éstos se encuentran regulados por la LBRL, añadiendo limitaciones importantes a la constitución y mantenimiento de los mismos.

\section{Objetivo de la reforma}

El propósito de la reforma del régimen jurídico de los consorcios llevada a cabo por la LERSAL tiene un claro antecedente y justificación en la aprobación de la LOEPSF en el año 2012, precedida de la reforma de la Constitución que tuvo lugar pocos meses antes, para incorporar al art. 135 de la misma una determinada concepción del principio de estabilidad presupuestaria, a raíz de los compromisos sobre consolidación fiscal adquiridos con la Unión Europea. Todo ello en el contexto de crisis económica, y crisis de endeudamiento, al que nos hemos referido al comenzar este trabajo, y con base en la necesidad de reducir el gasto público por la vía de la racionalización y redimensionamiento del sector público instrumental, en concreto, en el marco de la LERSAL, el sector público local $^{27}$. Aunque estas medidas no se limiten a los consorcios locales, aprovechando ya para establecer disposiciones que van a afectar a todos los consorcios administrativos, senda en la que se seguirá en la segunda fase de la reforma, como ya tendremos ocasión de ver.

El propio Preámbulo de la LERSAL hace referencia a estos antecedentes con toda claridad, estableciendo como uno de sus objetivos básicos el de "racionalizar la estructura organizativa de la Administración local de acuerdo con los principios de eficiencia, estabilidad y sostenibilidad financiera". Esta racionalización, "incluye una revisión del conjunto de las entidades instrumentales que conforman el sector público local”, siendo el consorcio local, qué duda cabe, una de ellas. El Preámbulo habla claramente de "medidas de reducción de la dimensión del sector público local”, y de "la necesidad de controlar su actividad y racionalizar su organización". Expresamente, aunque no lo conecte con esta cuestión, hace referencia al final del mismo a la modificación de la LRJPAC, que está pensada exclusivamente para incidir sobre el régimen jurídico del consorcio.

Como vamos a ver a continuación, las medidas adoptadas por la LERSAL son especialmente gravosas para el consorcio, por razón de las importantes limitaciones que establece para la constitución y mantenimiento de los mismos, reduciendo en gran medida la flexibilidad que ha sido seña de identidad de esta figura. Cuando se presenta políticamente el proyecto de reforma, y se anuncia el propósito de reducir el número de consorcios existentes, se hace denunciando su elevado número, y acusando su mal funcionamiento. Lo primero será cierto, no lo negamos ${ }^{28}$, pero es cuestionable que sea un problema en sí mismo, puesto que la elevada utilización de una herramienta jurídica no es en principio una prueba de su fracaso, sino más bien de su éxito. Otra cosa es que su elevado uso se tache de ineficiente, o de insostenible, en atención a los fines que se persiguen. $Y$ entonces ya, sí, hablemos de lo segundo, consorcios que funcionan mal. Pero no partiendo de un prejuicio acerca de su funcionamiento, que bien puede evidenciar el desconocimiento y la ignorancia acerca de esta figura, y carecer de fundamento empírico alguno, o de una valoración detenida y meditada sobre lo que de bueno y lo que de malo tiene el consorcio. Esta premisa, claro está, obliga a discriminar a la hora de adoptar estas medidas, desde esta perspectiva, la de la sostenibilidad financiera y la eficiencia, que es la que finalmente adopta la Ley, algo más cuidadosa en su redacción final que en los primeros borradores normativos, en los que el consorcio parecía haberse convertido, junto con las mancomunidades y las entidades locales menores, en uno de los enemigos a batir $^{29}$.

De esta manera, puede afirmarse que, aún sin renunciar por entero a su objetivo, el texto final de la LERSAL establece una aplicación más flexible de la inicialmente prevista, principalmente tras la introducción de algunas modificaciones durante la tramitación del proyecto de ley en las Cortes. Lo iremos viendo con mayor detalle,

27 Véanse al respecto los trabajos de MARTínEZ-ALONSO CAMPS, J.L. (2014): 621 y 622, MEDINA GUERRERO, M. (2014): 86 y MELLADO RUIZ, L. (2014): 126 y ss.

28 Cuando se plantea la reforma el número de consorcios administrativos supera claramente los 1.000. En el ámbito local la información actualizada la proporciona la Base de Datos General de las Entidades Locales dependiente del Ministerio de Hacienda y Administraciones Públicas.

29 Al respecto, véase el análisis que hicimos de este tema en un primer momento en TOSCANO GIL, F. (2013). También en un sentido similar puede verse la valoración de JIMÉNEZ ASENSIO, R. (2014): 1. 
cuando toque, en las páginas que aún tenemos por delante, pero puede ya decirse, a modo de síntesis, que esta aplicación más flexible lo es en los tiempos (Disposición transitoria $6^{\mathrm{a}}$ LERSAL, Disposición adicional $9^{\mathrm{a}}$ LBRL, apartados 2 y 4) y en los supuestos de aplicación (Disposición adicional $13^{\mathrm{a}}$ y $14^{\mathrm{a}} \mathrm{LERSAL}$ ), estableciéndose importantes excepciones.

\section{La adscripción del consorcio}

En nuestra opinión, la novedad más significativa que ha traído la reforma efectuada por la LERSAL al consorcio administrativo, ha sido la obligación de adscribirlo a una de sus plurales Administraciones matrices, introducida por la nueva Disposición adicional $20^{\mathrm{a}}$ de la LRJPAC, acentuándose así la naturaleza de ente instrumental de éste ${ }^{30}$, en detrimento del fundamento asociativo. Se trata de una solución aplicable a todas las Administraciones Públicas, a todos los consorcios administrativos ${ }^{31}$, no solo a los consorcios locales, pues la reforma de la LERSAL en este punto lo es de la LRJPAC, no de la LBRL, bajo la rúbrica "Régimen jurídico de los consorcios".

Si bien, la concepción del consorcio que aquí hemos expuesto, ya partía de la configuración de éste como ente instrumental, lo que suponía su dependencia respecto de las Administraciones matrices que estaban en la base de la constitución del consorcio, lo cierto es que la ley no establecía una adscripción formal. Esto obligaba al operador jurídico, a falta de un criterio legal expreso, a interpretar los estatutos del consorcio, con base en los criterios jurisprudenciales que ya conocemos, para dilucidar con cuál o cuáles de las Administraciones de las que dependía éste existía una relación de dependencia mayor, que permitiera determinar el régimen jurídico aplicable a éste, por razón de la fuerza atractiva que ejerciera, también sobre su ordenamiento jurídico de procedencia, la Administración o Administraciones a las que éste estuviera más estrechamente vinculado.

Pero la norma establecida por la Disposición adicional $20^{\text {a }}$ de la LRJPAC no determina la adscripción sino por relación a una sola Administración, esto es, no cabe la adscripción del consorcio a una pluralidad de Administraciones Públicas, ni aunque éstas sean de naturaleza homogénea, y pudieran por ello determinar la aplicación de un régimen jurídico común a todas ellas. Como veremos al final de este apartado, esta solución no es inocua, y plantea problemas cuando se trata de armonizar con la solución que había establecido alguna ley autonómica.

Por otra parte, la adscripción lo será siempre a una Administración Pública, aún en el caso de que también formaran parte del consorcio entidades privadas sin ánimo de lucro. La enunciación expresa de esta limitación, en el apartado 3 de la nueva Disposición adicional $20^{\mathrm{a}}$ LRJPAC, resulta lógica y coherente con la condición de Administración Pública del consorcio, así como con las consecuencias que veremos que tiene la adscripción, pero también puede considerarse obvia y superflua. No obstante, la incorporación de la misma a la LRJPAC tiene de positivo el reconocimiento expreso por ésta, siquiera sea por vía indirecta, de la posibilidad de incorporar al consorcio entidades privadas sin ánimo de lucro. Aunque, como es sabido, esto ya era una opción desde la LBRL de 1985, dicha opción no había sido recibida como norma estatal básica para todos los consorcios administrativos por la LRJPAC.

La adscripción del consorcio la realizan sus estatutos, que no son libres a la hora de determinarla, viniendo obligados a elegir de entre una serie de criterios de prioridad, esto es, siguiendo un orden marcado por el apartado 2 de la Disposición adicional $20^{\mathrm{a}}$ de la LRJPAC. La Ley, con cierto afán exhaustivo, posiblemente con la intención de cubrir todos los supuestos posibles, enumera hasta un total de ocho criterios distintos. Lo que ocurre es que esa exhaustividad le lleva a un grado de detalle tal que termina por suponer la desagregación de criterios

30 Así se ha señalado también en JIMÉNEZ ASENSIO, R. (2014): 2. Por lo demás, la reforma que traerá consigo, en caso de aprobarse, la futura Ley de régimen del sector público, acentuará aún más esta naturaleza instrumental del consorcio, al exigir "previa autorización normativa singular" para su constitución (art. 98.1), como si se tratara de un organismo autónomo. También a las funciones propias de éstos recuerdan las actividades que, según el anteproyecto, podrán formar parte del objeto del consorcio, "actividades de fomento, prestacionales o de gestión común de servicios públicos" (art. 93.2).

31 Con la única excepción, en principio, de los consorcios a los que se refiere la Disposición adicional 14 a de la LERSAL, a los que nos referiremos más adelante. No obstante, lo cierto es que, con posterioridad, mediante la Ley 15/2014 (Disposición final $10^{a}$ ), se ha introducido ya al menos una nueva excepción. Esta Ley excluye del régimen de los consorcios establecido en la LRJPAC a los consorcios sanitarios, regulados por la Ley 15/1997, de 25 de abril, sobre habilitación de nuevas formas de gestión del Sistema Nacional de Salud. Tras la Ley 15/2014, la Ley 15/1997 establece que los consorcios sanitarios cuyo objeto principal sea la prestación de servicios del Sistema Nacional de Salud se regirán por su Disposición adicional única, aplicándose de forma supletoria la normativa que regula con carácter general el régimen de los consorcios administrativos. La misma disposición determina directamente la adscripción de los consorcios sanitarios a la Administración responsable de la gestión de estos servicios en su ámbito territorial de actuación, al margen, pues, de la aplicación de los criterios de adscripción establecidos por la LRJPAC. Por lo demás, en línea con lo establecido en la LRJPAC, se incide en la sujeción de estos consorcios al régimen de presupuestación, contabilidad y control de la Administración de adscripción, y en la obligación que tiene el órgano de control de ésta de llevar a cabo una auditoría de las cuentas anuales del consorcio. 
estrechamente relacionados entre $s^{\prime 2}{ }^{2}$. En realidad, los distintos criterios establecidos por el legislador pueden resumirse, en un ejercicio de síntesis que prescinde de la literalidad de la Ley, en los tres siguientes: primero, el control mayoritario o efectivo de los órganos de gobierno del consorcio33; segundo, la aportación económica mayoritaria al mismo34; y, tercero, el mayor número de habitantes o extensión territorial35.

Aunque pueda valorarse favorablemente la enunciación de estos criterios, en cuanto aporten seguridad, no por ello deben dejar de hacerse algunas consideraciones críticas a los mismos. Lo primero sobre los que nos gustaría llamar la atención, siguiendo en este punto a la profesora NIETO GARRIDO, es lo poco apropiado que resulta para un consorcio la utilización del último criterio enunciado. Como ha señalado esta autora, la composición heterogénea de la entidad consorcial hace poco adecuados criterios como la población o el territorio, para determinar la adscripción a una Administración territorial, y su naturaleza y régimen jurídico ${ }^{36}$. Pero también cabe señalar, en lo que hace al primero y al segundo de los criterios enumerados, lo extraño que resulta plantearse un escenario en el que éstos no vayan cogidos de la mano ${ }^{37}$.

Por último, hay que decir que, entre los criterios en que se desglosa el que aquí hemos enunciado como primero, aparece otro que no se entiende bien qué hace situado en ese orden, ni por qué está siquiera en la ley. Nos referimos al establecido en la letra d), relativo a la Administración que "disponga de un mayor control sobre la actividad del consorcio debido a una normativa especial”. En nuestra opinión, si lo que se quería era establecer una cláusula habilitadora de excepciones al régimen general de la LRJPAC, había sitios mejores en los que ubicarla dentro de la propia Ley. Igualmente, no nos parecen de recibo los términos tan amplios en los que está redactada, ni lo impreciso de la misma. Pero es que, además, sin hacer uso, al menos expresamente, de esta cláusula, el legislador estatal ha introducido ya una nueva excepción a la aplicación de estos criterios, cuando no hace ni un año de la aprobación de esta norma, la de los consorcios sanitarios que puede leerse en la Disposición final $10^{a}$ de la Ley $15 / 2014$.

Por otra parte, según el mismo apartado 2 de la Disposición adicional $20^{a}$ de la LRJPAC, la adscripción se realiza, atendiendo a los citados criterios de prioridad, por referencia a la situación del consorcio en el primer día del ejercicio presupuestario, para cada ejercicio presupuestario y por todo ese periodo. Una vez determinada la adscripción, no resulta muy factible imaginar una situación en la que el consorcio cambiara de adscripción en cada ejercicio presupuestario, por poco operativa, y conflictiva, máxime si implicara un cambio de su régimen jurídico ${ }^{38}$. Solo si el supuesto de hecho enunciado por algún criterio determinante cambiara de un periodo para otro, podría plantearse tal hipótesis. Piénsese que incluso en el caso de que todos los criterios enunciados llevaran a una situación de empate que pudiera justificar una cierta alternancia, el último de los criterios permitiría normalmente alcanzar el desempate.

Una vez analizada la forma en que se realiza la adscripción, cabe hacerse la pregunta más importante de todas, qué consecuencias tiene ésta, esto es, para qué se determina la adscripción del consorcio a una Administración Pública. Si se aborda esta cuestión desde la perspectiva de los conflictos que se han producido en los últimos años, solucionados por la jurisprudencia ya conocida, y abordados por alguna ley autonómica, se responderá bajo el prejuicio de que la LERSAL articula la adscripción del consorcio a una determinada Administración Pública para poder fijar el régimen jurídico aplicable al mismo. Pero lo cierto es que ésta no es la perspectiva de la que parte la LERSAL, a la que le preocupa, principalmente, el control económico-financiero del consorcio, por lo que, lo que supone la adscripción es la sujeción de éste "al régimen de presupuestación, contabilidad y control" de la Administración a la que se adscribe, según se dice expresamente en el apartado 4 de la Disposición adicional $20^{a}$ LRJPAC.

32 En el mismo sentido, véase NIETO GARRIDO, E. (2014a): 373 y 374.

33 Este criterio enunciado por nosotros, es una síntesis de los siguientes criterios listados, por este orden, en el apartado

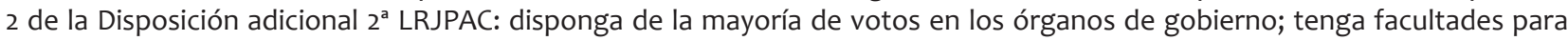
nombrar o destituir a la mayoría de los miembros de los órganos ejecutivos; tenga facultades para nombrar o destituir a la mayoría de los miembros del personal directivo; y tenga facultades para nombrar o destituir a la mayoría de los miembros del órgano de gobierno.

34 En este caso, lo que la LRJPAC dice es: letra f), financie en más de un cincuenta por cien o, en su defecto, en mayor medida la actividad desarrollada por el consorcio, teniendo en cuenta tanto la aportación del fondo patrimonial como la financiación concedida cada año, y, letra g), ostente el mayor porcentaje de participación en el fondo patrimonial.

35 En su literalidad, lo que dice la letra h) de la Disposición adicional $2^{\text {a }}$ de la LRJPAC es que "tenga mayor número de habitantes o extensión territorial dependiendo de si los fines definidos en el estatuto están orientados a la prestación de servicios, a las personas, o al desarrollo de actuaciones sobre el territorio".

36 Cfr. NIETO GARRIDO, E. (2014a): 374 y 375.

37 Lo que también ha sido apuntado por NIETO GARRIDO, E. (2014a): 374.

38 En una línea similar, véase GONZÁLEZ BUSTOS, M.A. (2014): 530 y 531. 
Con la excepción de lo relativo al régimen del personal del consorcio, que sí se dice expresamente en la Ley que vendrá dado por el de la Administración de adscripción, como expondremos en el siguiente epígrafe, no se explicita en ningún sitio qué ocurre con el resto del régimen jurídico del consorcio que no guarde relación directa con la vertiente económico-financiera. No aclara la Ley si, en buena lógica, le son también de aplicación el resto de las disposiciones del ordenamiento de referencia de la Administración a la que se adscriba. Es cierto que, el apartado 1 de la misma Disposición adicional $20^{\mathrm{a}} \mathrm{LRJPAC}$, se refiere expresamente al régimen orgánico y funcional del consorcio, junto con el financiero, pero lo hace exclusivamente para exigir que éste venga determinado por sus estatutos, sin que aparezca ligado necesariamente en la dicción legal al de la Administración de adscripción 39 . Ante este problema, se pueden sostener dos tesis, que pasamos a exponer a continuación, adelantando ya, como punto de partida, que nosotros abogamos por la primera.

La primera tesis sería que la LRJPAC solo determina la sujeción del consorcio al régimen de presupuestación, contabilidad y control, así como de personal, de la Administración a la que se adscribe. Esta es la tesis literal, que se atiene a lo que dice la Ley, ni más ni menos. Bajo esta tesis, para determinar el resto del régimen jurídico del consorcio habría que estar a lo dispuesto en sus estatutos, así como, en su caso, en la legislación autonómica de desarrollo, si ésta hubiera abordado expresamente esta cuestión. En el caso de que los criterios utilizados no fueran los mismos, esta tesis podría conducir a una situación en la que el consorcio estuviera sujeto a dos ordenamientos jurídicos distintos, uno que discipline su régimen de presupuestación, contabilidad, control, y de personal, y otro que determine el resto de su régimen jurídico. Por el contrario, si los criterios fueran coincidentes, el ordenamiento jurídico aplicable al consorcio sería el mismo a todos los efectos.

La segunda tesis consistiría en mantener que, aunque la LRJPAC no lo diga expresamente, la adscripción del consorcio implicaría su sujeción al régimen jurídico de la Administración a la que se adscriba a todos los efectos, no solo en lo que hace al régimen de presupuestación, contabilidad, control, y personal. Esta tesis puede parecer más operativa y armoniosa, por cuanto sujeta al consorcio en todo caso al mismo ordenamiento. Puede alegarse que es mejor solución desde el punto de vista de la seguridad jurídica, aunque, ciertamente, la seguridad jurídica no implica necesariamente ausencia de reglas complejas, sino existencia de reglas ciertas y no contradictorias. $Y$, además, como veremos, esta tesis chocaría con la opción ejercida por algún legislador autonómico, por razón de la utilización de criterios distintos.

No obstante, sí podría defenderse la aplicación supletoria de los criterios de la LRJPAC, para el caso de que ni los estatutos del consorcio ni el legislador autonómico hubieran establecido criterio alguno al respecto ${ }^{40}$. En este supuesto el consorcio se sujetaría, en todo caso, al mismo ordenamiento jurídico, que sería el de la Administración Pública de adscripción.

Por lo demás, la sujeción al régimen de presupuestación, contabilidad y control de la Administración de adscripción genera, según se detalla en el apartado 4 citado, la obligación, a cargo del órgano de control de ésta, de realizar una auditoría de las cuentas anuales del consorcio. A su vez, trae consigo la inclusión del consorcio en la cuenta general de la Administración a la que se adscribe, formando también parte de los presupuestos de la misma. Dicho crudamente, la Administración de adscripción va a cargar con el consorcio en sus presupuestos, lo que no resultará superfluo a la hora de determinar, conforme a la LOEPSF, si ésta respeta o no la obligación de guardar equilibrio presupuestario o de no incurrir en déficit ${ }^{41}$.

Las normas que en este epígrafe hemos analizado habían de tenerse en cuenta en la adaptación de los estatutos que debían realizar los consorcios ya existentes en el plazo de un año desde la entrada en vigor de la

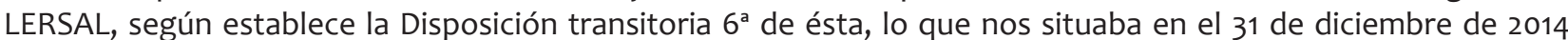
como fecha tope. Pero para el caso de que tal adaptación trajera consigo un cambio en el régimen jurídico del personal del consorcio, o en su régimen presupuestario, contable o de control, la aplicación se difería al 1 de enero del año siguiente, esto es, teniendo en cuenta el comienzo del siguiente ejercicio presupuestario, lo que suponía tomar como referencia el 1 de enero de $2015^{42}$.

39 Este problema ha sido destacado también por KONINCKX FRASQUET, A. (2014): 582.

40 En este mismo sentido se ha pronunciado NIETO GARRIDO, E. (2014a): 372 y 373.

41 Para la profesora NIETO GARRIDO, esta solución "va a suponer un duro revés para la buena salud de la institución consorcial”, que "conllevará la disminución del número de consorcios existentes y el declive del uso de la figura consorcial a favor de otras entidades instrumentales". Cfr. NIETO GARRIDO, E. (2014a): 376. En el mismo sentido, véase JIMÉNEZ ASENSIO, R. (2014): 2 .

42 Esta segunda regla obedece, como se ha apuntado en JIMÉNEZ ASENSIO, R. (2014): 6, a razones obvias de ajuste al ciclo presupuestario. Por ello, según este mismo autor, si la adaptación se hiciera incumpliendo la Ley, después del 1 de enero de 2015, la referencia temporal habría de ser el 1 de enero de 2016. 
No nos gustaría finalizar este apartado sin dar cuenta de cómo la nueva regulación establecida en la Disposición adicional $20^{\circ}$ LRJPAC ha incidido sobre el régimen jurídico de determinados consorcios. Nos referimos a consorcios que, conforme a la legislación autonómica eran considerados entes locales, pero que con estas nuevas reglas pasan a formar parte del sector público autonómico, al menos a efectos del régimen de presupuestación, contabilidad, control y de personal, si se sigue la primera tesis que hemos expuesto, a todos los efectos si se sigue la segunda. Estamos pensando en el caso andaluz, que es en el que hemos detectado este problema, sin perjuicio de que lo que aquí digamos sea extrapolable a otras Comunidades Autónomas ${ }^{43}$.

El art. 78.3 de la Ley 5/2010, de 11 de junio, de Autonomía Local de Andalucía (en adelante LAULA), dispone que "los consorcios participados mayoritariamente por entidades locales y que persigan fines en materia de interés local se considerarán entidades locales de cooperación territorial a los efectos de esta ley". Bajo esta norma, un consorcio compuesto mayoritariamente por entidades locales, con una participación significativa, aunque no mayor que la local, de Administraciones de otro orden territorial, como la autonómica, es considerado en todo caso un ente local.

El problema viene dado porque la nueva redacción de la LRJPAC exige la adscripción a una sola Administración Pública, no siendo posible la adscripción formal a varias de ellas. Un consorcio en el que la Administración autonómica no tuviera una participación mayor que el que resulte de la suma de la participación correspondiente a todas las entidades locales que lo integran, podrá ser una entidad local conforme al art. 78.3 LAULA. Pero con la peculiaridad de que, en la medida en que ninguna de estas últimas tuviera una cuota de participación o control mayor que la primera, bajo los criterios de la LRJPAC el consorcio habría de adscribirse necesariamente a la Administración autonómica, al menos a efectos del régimen de presupuestación, contabilidad, control y personal, rigiéndose para todo lo demás por el Derecho de las entidades locales andaluzas ${ }^{44}$.

\section{El personal del consorcio}

La misma Disposición adicional $20^{\mathrm{a}}$ de la LRJPAC que acabamos de comentar, en su apartado 5 , establece limitaciones al personal de los consorcios, aplicables a todos los consorcios administrativos, no solo a los consorcios locales, aunque hayan venido de la mano de la LERSAL, pero introducidas, como se ha señalado, en la LRJPAC. La Ley dispone que el personal al servicio de los consorcios podrá ser funcionario o laboral, hasta aquí nada nuevo, pero que éste deberá proceder exclusivamente de una reasignación de puestos de trabajo de las Administraciones participantes. En esto último reside la novedad, en la prohibición de contar con personal propio.

Según la Ley, el régimen jurídico de este personal será el de la Administración Pública a la que se adscriba el consorcio, como ya habíamos apuntado en el epígrafe anterior, y sus retribuciones en ningún caso podrán superar las establecidas para puestos de trabajo equivalentes en aquella ${ }^{45}$.

Nos encontramos aquí con una serie de medidas coherentes con la búsqueda de racionalización organizativa pretendida por la LERSAL ${ }^{46}$, acordes a la naturaleza instrumental de los consorcios, pero que, en su aplicación práctica, cuando se desciende a la realidad, plantean importantes problemas. El primero de los cuales es la imposibilidad de encontrar personal adecuado en las Administraciones consorciadas, en los casos en que las funciones del consorcio sean muy específicas, y lo que necesite éste sea, pongamos por caso, un médico, un

43 El problema que vamos a exponer ha sido también detectado por GONZÁLEZ BUSTOS, M.A. (2014): 526 y KONINCKX FRASQUET, A. (2014): 583.

44 Este es el caso de los consorcios metropolitanos de transporte andaluces, participados mayoritariamente por entidades locales (un 55\%, del que un 50\% corresponde a los Ayuntamientos del área metropolitana, y un $5 \%$ a la Diputación provincial de la misma), siendo la Administración autonómica andaluza minoritaria con respecto a las mismas (un $45 \%$ de participación), pero siendo en todo caso la Administración Pública de adscripción, con la aplicación de los criterios establecidos en la Disposición adicional $20^{\mathrm{a}}$ LRJPAC. La aplicación a estos consorcios locales del régimen de presupuestación, contabilidad y control de la Administración de la Junta de Andalucía no es en realidad extraña, puesto que ya se les venían aplicando algunas normas propias del mismo, por exigencia directa de la Ley 2/2003, de 12 de mayo, de Ordenación de los Transportes Urbanos y Metropolitanos de Viajeros en Andalucía (arts. 27.2 y 4), como puede verse en el análisis que hicimos de este caso en TOSCANO GIL, F. (2011b): 215-217.

45 Por otra parte, tratándose de consorcios locales, el nuevo art. 103.bis LBRL dispone que la masa salarial del personal laboral del sector público local, que ha de ser aprobada anualmente por las corporaciones locales ajustándose a una serie de límites y condiciones establecidos por la Ley de Presupuestos Generales del Estado, incluirá la de los consorcios adscritos a las mismas.

46 En el mismo sentido, véase KONINCKX FRASQUET, A. (2014): 597 y 598. 
director de orquesta o un bombero ${ }^{47}$. Un segundo problema importante sería, en el caso de que estas medidas no se entendieran como de futuro, el de su aplicación a los consorcios existentes en el momento de entrada en vigor de la LERSAL. ¿Qué ocurre con el personal propio que ya tuvieran estos consorcios?

La aplicación directa de la Ley, aún esperando a la adaptación de los estatutos en los tiempos marcados por la Disposición transitoria $6^{a}$, exigiría proceder a la extinción de los contratos de trabajo del personal laboral propio y a la reasignación de funcionarios a la Administración de adscripción ${ }^{48}$. Pero, quizás una solución más prudente, que atendiera a la falta de auténticas reglas transitorias sobre esta cuestión en la LERSAL, abogaría por entender que estamos ante una prohibición de futuro. Ésta debería leerse como la imposibilidad de contar con personal propio en los nuevos consorcios que se constituyan, o de aumentar el que ya exista en los consorcios vigentes, pero, en ningún caso, la obligación de extinguir la relación con el que ya lo sea49.

Sin embargo, no contribuyen a esta interpretación las excepciones establecidas por la propia LERSAL, que gravitan sobre consorcios constituidos antes de la entrada en vigor de la misma. De tal modo que, a sensu contrario, debería entenderse que solo estos consorcios preexistentes, y no los restantes, se salvan de la obligación de aplicar la prohibición de contar con personal propio que establece el apartado 5 de la Disposición adicional $20^{a}$ LRJPAC. Pasamos, a continuación, a exponer las mencionadas excepciones ${ }^{50}$.

En primer lugar, la establecida por la Disposición adicional $13^{\text {a }}$ de la LERSAL, que permite tener personal propio a los consorcios que, habiéndose constituido antes de la entrada en vigor de esta Ley, presten servicios mínimos de los referidos en el art. 26 LBRL. Esta excepción de la regla general parece atender al carácter estructural de la prestación de servicios mínimos, aunque, como se advertirá, no es una excepción para los consorcios de este tipo que se hubieran de constituir en el futuro, sino solo para los preexistentes.

En segundo lugar, debe referirse la excepción definida por la Disposición adicional $14^{\text {a }}$ de la LERSAL, con la diferencia de que lo es no solo a la prohibición de tener personal propio, sino a todo el régimen jurídico introducido por la Disposición adicional $20^{\mathrm{a}}$ de la LRJPAC. La Ley se refiere a determinados consorcios, definidos en base a una serie de condiciones que han de darse de forma cumulativa, y que llevan a preguntarse seriamente si realmente tendrá lugar un caso en el que todas ellas se den, así como a qué tipo de consorcios se está haciendo referencia5. Se trata de "los consorcios, constituidos antes de la entrada en vigor de esta Ley, que: no tengan la consideración de Administración Pública a efectos del Sistema Europeo de Cuentas, estén participados por Entidades Locales y entidades privadas, no estén incursos en pérdidas durante dos ejercicios consecutivos y no reciban ni hayan recibido subvenciones de las Administraciones Públicas en los cinco ejercicios anteriores al de entrada en vigor de esta Ley con independencia de las aportaciones a las que estén obligados los entes consorciados". Ahí es nada.

Por último, debemos apuntar que, tratándose de consorcios locales, la LERSAL establece una prohibición adicional, la de que puedan tener personal eventual, ya sea propio o adscrito. Esta limitación se deriva claramente del nuevo art. 104.bis LBRL, cuyo apartado 3 establece que, salvando municipios y provincias, el resto de entidades locales o sus organismos dependientes, entre los que consideramos que estaría el consorcio, "no podrán incluir en sus respectivas plantillas, puestos de trabajo cuya cobertura corresponda a personal eventual". Tampoco cabe plantearse la opción de que éste se incorpore como personal adscrito, pues el siguiente apartado, el 4, aunque admite que el personal eventual no se asigne a los servicios generales de la entidad local en cuya plantilla aparezca consignado, lo hace solo excepcionalmente, y en términos muy restrictivos. Solo cabe asignarlo, "con carácter funcional, a otros de los servicios o departamentos de la estructura propia de la entidad local, si así lo reflejare

47 Este problema, junto con otros tantos que genera la nueva regulación, ha sido señalado en CASTILLO BLANCO, F. (2014): 909. Debemos apuntar aquí que, el anteproyecto de LRJSP al que ya nos hemos referido, contempla una posible solución, al disponer, en el segundo párrafo de su art. 96, que "excepcionalmente, cuando no resulte posible contar con personal procedente de una reasignación de puestos de trabajo de las Administraciones participantes en el consorcio en atención a la singularidad de las funciones a desempeñar, el Ministerio de Hacienda y Administraciones Públicas, u órgano competente de la Administración a la que se adscriba el consorcio, podrá autorizar la contratación directa de personal por parte del consorcio para el ejercicio de dichas funciones".

48 En esta línea, véase NIETO GARRIDO, E. (2014a): 377 y JIMÉNEZ ASENSIO, R. (2014): 7.

49 En tal sentido, puede verse KONINCKX FRASQUET, A. (2014): 599.

50 La Ley 15/2014 ha introducido una tercera excepción, de mayor alcance que las anteriores, por cuanto permite no ya conservar el personal propio que se tuviera, sino tenerlo en el futuro. Nos estamos refiriendo a la norma establecida para los consorcios sanitarios, en la Ley 15/1997, de 25 de abril, sobre habilitación de nuevas formas de gestión del Sistema Nacional de Salud (apartado 3 de su Disposición adicional única), que les permite tener no solo personal funcionario, estatutario o laboral procedente de las Administraciones participantes, sino también personal laboral contratado directamente por el consorcio, o sea, personal laboral propio.

51 De la misma opinión es NIETO GARRIDO, E. (2014a): 379. 
expresamente su reglamento orgánico". Difícilmente, si no es desde una interpretación muy forzada, podrá considerarse "estructura propia de la entidad local" al consorcio ${ }^{52}$. No creemos que la Ley esté pensando en esto.

\section{Limitaciones a la constitución de nuevos consorcios}

Entramos ya con este apartado en el análisis de las disposiciones que son solo de aplicación a los consorcios participados por entidades locales, en cuanto se introducen por la LERSAL por la vía de la reforma de la LBRL, no de la LRJPAC, como las anteriores. La primera de éstas es un nuevo art. 57 de la LBRL, que es el que siempre ha contemplado en ésta, junto con el 87 , a los consorcios locales. Ahora habrán de tenerse en cuenta también, en la forma en que luego veremos, las nuevas Disposiciones adicionales $9^{\mathrm{a}}$ y $12^{\mathrm{a}}$ de la LBRL, como conformadoras del régimen jurídico de éstos, que ya no se limita a los clásicos arts. 57 y 87.

Pero en este momento en lo que nos debemos centrar, para tratar el tema que da título a este epígrafe, es en el nuevo art. 57 LBRL. Lo primero que procede decir es que este precepto establece limitaciones de futuro, por cuanto se trata de limitaciones a la constitución de consorcios, a la constitución, como es lógico, de nuevos consorcios.

En este punto, se establece una regla de partida, que solo se podrán crear consorcios cuando no se pueda alcanzar el mismo fin con un convenio, y siempre que, en términos de eficiencia económica, la utilización del consorcio permita una asignación más eficiente de los recursos económicos. Por tanto, con esta nueva norma, la cooperación entre la Administración local y otras Administraciones Públicas regulada por este artículo deberá hacerse ahora preferentemente mediante convenios interadministrativos, y, subsidiariamente, constituyendo un consorcio. Se vuelca así en la Ley un prejuicio acerca de la funcionalidad y eficacia de los consorcios, y se limita la autonomía y la discrecionalidad de las Administraciones Públicas para decidir, en el ejercicio de su potestad de autoorganización, la forma de cooperación, viéndose ahora obligadas a motivar si en lugar de elegir un convenio deciden constituir un consorcio ${ }^{53}$.

A esto se añade otra limitación, se dice en el precepto objeto de nuestra atención que, "en todo caso, habrá de verificarse que la constitución del consorcio no pondrá en riesgo la sostenibilidad financiera del conjunto de la Hacienda de la Entidad Local de que se trate, así como del propio consorcio, que no podrá demandar más recursos de los inicialmente previstos".

Finalmente, tanto para la suscripción de convenios como para la constitución de nuevos consorcios, se dispone que, "deberán mejorar la eficiencia de la gestión pública, eliminar duplicidades administrativas y cumplir con la legislación de estabilidad presupuestaria y sostenibilidad financiera". Nos encontramos aquí con una serie de cláusulas que, en nuestra opinión, deben calificarse, como mínimo, de desafortunadas. Lo último que se añade resulta ciertamente redundante, pues, ¿cómo podría pretenderse no cumplir la LOEPSF? ¿Es preciso añadir esto en la Ley? Más que eliminar duplicidades administrativas, cabría decir no generarlas, piénsese que el ejercicio de la competencia no desaparece con la utilización de una fórmula de cooperación, únicamente se pone en común, simplemente se presta ahora por otro ente. ¿Cómo podría eliminarse así una duplicidad? Más bien habría que contentarse con no incurrir en ella. Y, en fin, el propósito de mejorar la eficiencia de la gestión pública, aunque loable, habrá que ver cómo se mide, y, sobre todo, cómo se controla y se hace cumplir54.

\section{Limitaciones derivadas de la Disposición adicional 9 a LBRL: redimensionamiento del sector público local}

Procede ahora analizar una serie de limitaciones que afectan no ya solo a la constitución de nuevos consorcios sino también al mantenimiento de los mismos, así como a la existencia de entidades dependientes de éstos. Estas limitaciones se establecen bajo la rúbrica "Redimensionamiento del sector público local", en la nueva Disposición adicional $9^{\text {a }}$ de la LBRL, introducida por la LERSAL. Por tanto, no son medidas específicas para los consorcios, sino para todo el sector público instrumental local55, incurriendo en el error de incluir en una misma disposición soluciones para entidades de naturaleza tan distinta ${ }^{56}$. Dentro de los consorcios, estas medidas se aplican exclusivamente a los consorcios participados por entidades locales, no siendo aplicables al resto de consorcios administrativos.

52 Así lo ha entendido también KONINCKX FRASQUET, A. (2014): 598.

53 En la misma línea, pueden verse las críticas formuladas por MEDINA GUERRERO, M. (2014): 84 y 85.

54 Al respecto, pueden verse las consideraciones que, con distinto alcance, aunque en todo caso crítico, se hacen sobre las cláusulas enunciadas en este precepto en JIMÉNEZ ASENSIO, R. (2014): 3, KONINCKX FRASQUET, A. (2014): 566-569, y NIETO GARRIDO, E. (2014a): 363.

55 Sobre la enorme complejidad de estas medidas se ha pronunciado, entro otros, MARTínEZ-ALONSO CAMPS, J.L. (2014): 623. Se trata, sin duda, de una de las disposiciones más intrincadas, además de desafortunadas, de la LERSAL.

56 Lo que también ha sido destacado en MARTínEZ-ALONSO CAMPS, J.L. (2014): 624. 
La primera de estas medidas, establecida en el apartado 1 de la citada Disposición adicional 9a LBRL, consiste en la prohibición, para las entidades locales territoriales del art. 3.1 LBRL, de constituir o participar en consorcios, si se encuentran bajo la vigencia de un plan de ajuste o económico-financiero. En este caso estamos ante una prohibición de futuro, que opera sobre las entidades locales que quieran constituir un nuevo consorcio o participar en uno ya existente. En nuestra opinión, se trata de una restricción que puede condicionar la viabilidad de la fórmula diseñada por el nuevo art. 26.2 LBRL, que prevé la utilización de consorcios para la prestación de determinados servicios en los municipios con población inferior a 20.000 habitantes, bajo la coordinación de la Diputación Provincial. Piénsese que no es difícil imaginar un escenario en el que algunos de estos municipios se encuentren realizando el ajuste exigido por la LOEPSF. En esa situación éstos no podrían formar parte del consorcio previsto por el art. 26.2 LBRL como solución a sus problemas, dada la prohibición establecida por la Disposición adicional $9^{a}$ de la misma Ley. A su vez, las pretendidas ventajas de las economías de escala cuando se aplican las fórmulas de gestión compartidas previstas en la Ley, quedarían en entredicho, en cuanto algunos de los municipios existentes en el territorio se verían excluidos de su aplicación, quedando fuera del círculo delimitado57.

La segunda medida, apartado 2 de la misma Disposición adicional, consiste en la obligación de disolver aquellos consorcios locales que se encuentren en situación de desequilibrio financiero a la entrada en vigor de la LERSAL ${ }^{58}$. La disolución no es automática, sino que se puede salvar por la vía de un plan de corrección de dicho desequilibrio. Los tiempos para ello son los siguientes: plazo de dos meses desde la entrada en vigor de la Ley para aprobar dicho plan, contando con el informe previo del interventor; 31 de diciembre de 2014 como fecha máxima para cumplir con el mismo; si no se lograra corregir el desequilibrio en dicho plazo, entonces se debe proceder ya a la disolución del consorcio en un máximo de seis meses, a contar desde la liquidación del presupuesto del ejercicio 201459; finalmente, de no llevar a cabo la disolución, tal y como manda la Ley, ésta sería automática a 1 de diciembre de 2015 .

Estos plazos se relajan para determinados consorcios locales, introduciéndose una nueva excepción en la aplicación de la LERSAL, en la línea de las que ya hemos visto en las páginas precedentes, que flexibilizan el rigor de la Ley, si bien, esta vez, la excepción lo es en los tiempos, pues la norma se aplica igualmente, pero se demora su aplicación. De esta forma, los plazos a los que nos hemos referido en el párrafo anterior se amplían, hasta 31 de diciembre de 2015 el primero, fecha para corregir el desequilibrio, 1 de diciembre de 2016 el segundo, como fecha de la disolución automática. Los consorcios locales que se incluyen bajo este supuesto, son los que presten determinados servicios que la Ley califica de esenciales, y que recoge bajo la siguiente enumeración: abastecimiento domiciliario y depuración de aguas, recogida, tratamiento y aprovechamiento de residuos, y transporte público de viajeros. Nótese que, en este caso, la excepción no gravita sobre todos los consorcios locales prestadores de los servicios mínimos del art. 26 LBRL, como ocurría con los de la Disposición adicional $13^{\text {a }}$ LERSAL, a los que se excluía de la prohibición de tener personal propio. Aquí la exclusión se limita a los consorcios que presten solo algunos de estos servicios, no todos, sino los enumerados expresamente en el precepto que comentamos.

La tercera medida, establecida en el apartado 3 de la Disposición adicional que venimos analizando, vuelve a ser una prohibición de futuro, como la primera, consistente en este caso en la prohibición para los consorcios locales de constituir, participar en la constitución o adquirir nuevos entes del tipo que sean. Al mismo tiempo, se prohíbe a las entidades instrumentales del sector público local que constituyan o participen en la constitución de nuevos consorcios. Esta limitación ha sido enunciada, de forma expresiva por la doctrina, como la prohibición de crear entidades instrumentales de segundo grado o de segundo nivel ${ }^{60}$. De tal modo que si un consorcio es ya una entidad instrumental, de primer grado, lo que se impide es la constitución por éste de entidades instrumentales, públicas o privadas, generando así una entidad instrumental de segundo grado. Igualmente, no se permite que una entidad instrumental cree un consorcio, que se consideraría, bajo esta perspectiva, entidad de segundo grado.

Se trata de una limitación que choca frontalmente con la conocida previsión de normas estatales previas, como el art. 110.5 TRRL y el 40 RSCL, según los cuales, los consorcios pueden utilizar cualquiera de los modos de gestión previstos en la legislación de régimen local $^{61}$. Está claro que, tras la reforma, no cabe la gestión mediante la constitución de entidades instrumentales, del tipo que sea. Esta solución genera un problema importante, porque

57 Este problema ha sido también señalado por KONINCKX FRASQUET, A. (2014): 589 y 590.

58 Según el mismo apartado 2 de la Disposición adicional $9^{a}$ LBRL, esta situación de desequilibrio financiero se referirá a la necesidad de financiación del consorcio en los términos del Sistema Europeo de Cuentas.

59 Al respecto, véanse las precisiones que, sobre el modo de calcular estos plazos, se hacen en MARTínEZ-ALONSO CAMPS, J.L. (2014): 633.

60 Ver JIMÉNEZ ASENSIO, R. (2014): 5, MARTÍNEZ-ALONSO CAMPS, J.L. (2014): 634, y NIETO GARRIDO, E. (2014a): 354.

61 Estos preceptos deben entenderse derogados, como ha señalado KONINCKX FRASQUET, A. (2014): 600 y 601. Debe señalarse que, en cualquier caso, el anteproyecto de LRJSP prevé expresamente la derogación del art. 110 TRRL. 
va contra una práctica acrisolada en el mundo local, la utilización del consorcio como técnica de cooperación interadministrativa, acompañada de la posterior creación de una sociedad mercantil para la gestión del servicio ${ }^{62}$.

La última medida, relacionada con la anterior, y prevista en el apartado 4 de la Disposición adicional $9^{\text {a }}$ de la LBRL, trata de responder a qué ocurre con las entidades instrumentales de segundo grado existentes a la entrada en vigor de la LERSAL. O sea, establecida la prohibición de futuro de su creación, se trata ahora de determinar qué se hace con las ya existentes. Lo primero que debe decirse al respecto es que esta medida no recae de forma indiscriminada sobre toda entidad instrumental de segundo grado, sino solo sobre aquellas que, a la entrada en vigor de la Ley, no estén en situación de superávit, equilibrio o resultados positivos de explotación.

Dentro de éstas, la Ley distingue dos supuestos, por un lado, las entidades de segundo grado que estuvieran controladas exclusivamente por entidades vinculadas o dependientes de entes locales territoriales, y, por otro lado, aquellas en las que el control no se ejerciera con carácter exclusivo. Como se ha ocupado de aclarar MARTÍNEZ-ALONSO CAMPS, por control exclusivo debe entenderse posición mayoritaria63.

Para los casos en que el control no se ejerza con carácter exclusivo, se dispone la obligación de transmitir la participación que se tuviera en las entidades instrumentales de segundo grado, en un plazo de tres meses desde la entrada en vigor de la Ley. Esto es, dado el supuesto de hecho de un consorcio con participación no mayoritaria en una entidad instrumental, o de una entidad instrumental con participación no mayoritaria en un consorcio, en ambos casos, no estando en situación de superávit, equilibrio o resultados positivos de explotación, deberán transmitir su participación en el plazo de tres meses establecido por la Ley ${ }^{64}$. No aclara ésta a quién debe transmitirse dicha participación. Entendemos que a la entidad que tenga el control mayoritario.

El otro tipo de entidades de segundo grado a las que se refiere la Ley es aquellas en las que el control fuera exclusivo, esto es, mayoritario. O sea, un consorcio dominado mayoritariamente por una entidad instrumental, o una entidad instrumental dominada mayoritariamente por un consorcio, que no se encuentren en situación de superávit, equilibrio o resultados positivos de explotación. En esta situación, a lo que obliga la norma es a adscribir o vincular estas entidades de segundo grado directamente a una entidad local territorial, o bien a disolverlas, en ambos casos en el plazo de tres meses desde que entrara en vigor la Ley. Si se opta por la disolución, el proceso de liquidación deberá llevarse a cabo en un plazo de tres meses a contar desde esta última. En cualquier caso, de no cumplir estas normas, tendrá lugar la disolución automática en un plazo de seis meses desde la entrada en vigor de la Ley.

Tampoco en este supuesto ha precisado la Ley a qué entidad local territorial debe adscribirse o vincularse el ente de segundo grado. En el caso de tratarse de una entidad instrumental dependiente de un consorcio, la vinculación podría hacerse a la entidad local de adscripción del consorcio. Tratándose de un consorcio dependiente de un ente instrumental, la solución más lógica sería su adscripción a la entidad local de la que depende dicho ente, siempre y cuando así resultara de la aplicación de los criterios de la Disposición adicional 20ªRJPAC.

Todos los plazos que aquí hemos indicado, se amplían en un año más cuando la entidad instrumental de segundo grado estuviera prestando algunos de los servicios a los que ya nos referimos al enunciar la excepción a la norma del apartado 2 de esta misma Disposición: abastecimiento domiciliario y depuración de aguas, recogida, tratamiento y aprovechamiento de residuos, y transporte público de viajeros. Nuevamente, se trata de una excepción en los tiempos, no se excluye la aplicación de la norma, simplemente se demora.

\section{Limitaciones al número máximo de los miembros de los órganos de gobierno del consorcio y a la existencia y retribuciones del personal directivo}

Para terminar con las novedades que ha traído la LERSAL al régimen jurídico de los consorcios, hay que detenerse en la nueva Disposición adicional $12^{\mathrm{a}} \mathrm{LBRL}$, aplicable únicamente a los consorcios que formen parte del sector público local, por tanto, no a todos los consorcios administrativos, como denota su ubicación dentro de la LBRL. En esta nueva disposición se introducen una serie de limitaciones que inciden sobre el número de directivos que puede tener un consorcio, y sus retribuciones, así como sobre el número máximo de miembros de los órganos

62 Los problemas reales que genera esta prohibición han sido apuntados en MARTínEZ-ALONSO CAMPS, J.L. (2014): 634.

63 Cfr. MARTÍNEZ-ALONSO CAMPS, J.L. (2014): 636.

64 Y ello con independencia de que, como se ha señalado en MARTíNEZ-ALONSO CAMPS, J.L. (2014): 639, la expresión "proceder a la transmisión de su participación" no sirva para todo tipo de entidad. 
de gobierno de éste ${ }^{65}$. Igual que en la disposición que analizamos en el epígrafe anterior, no son normas exclusivas de los consorcios las que aquí se establecen, sino de todas las entidades instrumentales del sector público local. Si bien aquí, como es lógico, las miraremos desde la óptica de su aplicación a éstos.

En ambos casos, las limitaciones parten de un presupuesto inicial, la obligación que se establece para el Pleno de la entidad local de que se trate, de clasificar sus entidades instrumentales en tres grupos, atendiendo a los siguientes criterios: volumen o cifra de negocio, número de trabajadores, necesidad o no de financiación pública, volumen de inversión y características del sector en que desarrolla su actividad. Como podrá apreciarse no todos ellos son de aplicación a una entidad como el consorcio, y, en cualquier caso, son criterios lo suficientemente abiertos como para que condicionen en exceso la discrecionalidad del Pleno a la hora de efectuar la clasificación. Esta clasificación en tres grupos va a ser la que determine los límites, por un lado, al número máximo de miembros de los órganos de gobierno del consorcio, y, por el otro, al número de directivos de éste, incluyendo su retribución. Ambas cuestiones dependerán de que el consorcio se encuentre integrado en un grupo u otro.

En lo que hace al número de directivos, la Ley se limita a establecer que deberá fijarse un número mínimo y máximo para cada uno de estos tres grupos, incluyendo la cuantía máxima de la retribución total, con determinación del porcentaje máximo del complemento de puesto y variable ${ }^{66}$. La LBRL no establece un límite a la cuantía máxima de la retribución total que pueda fijarse por la entidad local, sino que se remite al establecido anualmente en la Ley de presupuestos generales del Estado67.

Por otra parte, la clasificación también determina el "número máximo de miembros del consejo de administración y de los órganos superiores de gobierno o administración de las entidades, en su caso", según establece la Ley. Para los consorcios que se incluyan en el grupo 1 un máximo de 15 miembros, para los del grupo 2 un máximo de 12, y para los del grupo 3 un máximo de 9. En este caso, a diferencia del anterior, el límite máximo sí se introduce con toda precisión en la LBRL. Y ello genera, como vamos a comentar ahora, no pocos problemas, nuevamente por la solución de meter en una misma disposición entidades de naturaleza tan diversa, incluyendo al consorcio entre ellas. La dificultad principal viene dada por la respuesta que se dé a la pregunta qué debe entenderse por “consejo de administración” o por “órganos superiores de gobierno o administración” del consorcio.

Una primera interpretación puede ser que se refiere al órgano plenario de éste, teniendo en cuenta que existen consorcios en los que el órgano plenario se denomina precisamente consejo de administración ${ }^{68}$. Pero esta lectura ofrece el problema de que en cuanto un consorcio esté participado por un número de entidades superior al número de miembros que la Ley permite que puedan formar parte del consejo de administración, según el grupo en el que se encuadre, estas entidades, que son miembros de pleno derecho del consorcio, se quedarían sin representación en el órgano plenario del mismo, lo que es a todas luces descabellado.

Una segunda interpretación, menos conflictiva, pero tampoco exenta de problemas, es entender que no se está haciendo referencia al órgano plenario, sino a órganos colegiados ejecutivos o de gestión ordinaria del consorcio, para el caso de que existan, claro está, puesto que estas funciones también pueden ser asumidas por un órgano unipersonal, normalmente la presidencia del consorcio ${ }^{69}$. El problema aquí sigue existiendo, es exactamente el mismo. Pero con la diferencia de que, en nuestra opinión, puede considerarse menos grave la ausencia de representantes en el órgano ejecutivo o de gestión que en el órgano plenario. Piénsese que incluso es posible que, como se ha dicho, este órgano ejecutivo no sea colegiado. En cualquier caso, bajo esta interpretación, se salvaría la representación de todas las entidades asociadas en la organización del consorcio, aunque fuera a través del órgano plenario.

65 Esta disposición ha sido duramente criticada por la profesora NIETO GARRIDO, que entiende que se trata de una injerencia excesiva en la autonomía local constitucionalmente garantizada, de difícil amparo en el art. 149.1.18 ${ }^{\mathrm{a}} \mathrm{CE}$, especialmente la regulación del número máximo de miembros del consejo de administración. Cfr. NIETO GARRIDO, E. (2014a): 358 y 359.

66 La misma Disposición concreta estos conceptos al señalar que las retribuciones a fijar en los contratos del personal directivo se clasifican, exclusivamente, en básicas y complementarias. Las retribuciones básicas lo serán en función de las características del consorcio e incluyen la retribución mínima obligatoria asignada. Las retribuciones complementarias comprenden un complemento de puesto y un complemento variable. El complemento de puesto retribuye las características específicas de las funciones o puestos directivos y el complemento variable retribuye la consecución de unos objetivos previamente establecidos.

67 No obstante, sí se sientan algunas reglas en la LBRL, como que las retribuciones en especie que, en su caso, se perciban computarán como parte de la retribución total a la hora de determinar su máximo.

68 Como en los consorcios metropolitanos andaluces. Como puede verse en TOSCANO GIL, F. (2011b): 178. Por el contrario, como es sabido, en las sociedades mercantiles locales el consejo de administración no es el órgano plenario, reservándose tal función a la junta general (art. 85 ter LBRL, y 89 y ss. RSCL).

69 Véase al respecto TOSCANO GIL, F. (2011b): 78 y 79. 
En ambos casos, se abogue por una interpretación u otra, estamos ante una solución que entra en abierta contradicción con una disposición estatal previa, el art. 110.4 TRRL70, según el cual, los “órganos de decisión” del consorcio "estarán integrados por representantes de todas las Entidades consorciadas, en la proporción que se fije en los Estatutos respectivos" 71 . De entenderse derogada esta disposición por la nueva norma estatal, los estatutos del consorcio deberían fijar ahora los criterios que permitan determinar qué entidades de las que integren el consorcio, y en qué proporción, estarán representadas en los distintos órganos de gobierno del mismo.

Finalmente, también cabe defender, como ha hecho con cierto ingenio KONINCKX FRASQUET, que esta norma no es aplicable a los consorcios, dado el inciso "en su caso", con el que termina el precepto transcrito72.

Una última cuestión de relevancia debe abordarse antes de cerrar este epígrafe ${ }^{73}$, la del momento a partir del cual estas limitaciones son de aplicación. El apartado 6 de la Disposición adicional que venimos comentando, establece un plazo máximo de tres meses para la adaptación de los estatutos del consorcio a estas nuevas previsiones, plazo que habrá de contarse desde la comunicación de la clasificación del consorcio en uno de los tres grupos de referencia. El problema es que la Ley no establece expresamente cuál es el plazo máximo para proceder a esta clasificación.

En nuestra opinión, en lo que hace a los consorcios, habría que estar al plazo común que establece la Disposición transitoria $6^{\text {a }}$ de la LERSAL para la adaptación de los estatutos a todo lo previsto en esta Ley, pues no tiene sentido abrir dos procesos distintos de modificación de los mismos. Por tanto, en el mismo proceso, bajo el mismo plazo que ya conocemos, se debería proceder por las entidades consorciadas a determinar la entidad de adscripción del consorcio, a la clasificación del mismo por el Pleno de ésta, en función de la cual se extraerán las consecuencias relativas al número máximo de miembros de sus órganos de gobierno, número y retribución de directivos, y, finalmente, a volcar todas estas previsiones exigidas por la Ley en los nuevos estatutos.

No obstante, la Ley exige que lo relativo al personal directivo se aplique antes del plazo de adaptación de los estatutos, por cuanto el mismo apartado 6 de la Disposición adicional $12^{\mathrm{a}}$ LBRL en el que nos hemos situado, dispone que, "el contenido de los contratos mercantiles o de alta dirección celebrados, con anterioridad a la entrada en vigor de esta Ley, deberá ser adaptados a la misma en el plazo de dos meses desde la entrada en vigor". Esta adaptación cuenta con una limitación, que "no podrá producir ningún incremento, en relación a su situación anterior". No lo dice la norma claramente, pero entendemos que se está refiriendo a un incremento de los derechos de este personal.

De esta forma, lo que parece que subyace a esta disposición es la intención de adoptar cuanto antes una medida que podría implicar una disminución del gasto público, si de ella resultara una retribución menor para el directivo público. Pudiendo también contemplarse un escenario en el que el contrato de éste tuviera que extinguirse, con lo que el ahorro sería aún mayor, como consecuencia de la disminución del número de directivos tras la clasificación ${ }^{74}$.

Obsérvese que, si el contenido del contrato depende de la clasificación, en la medida en que la retribución va ligada a ésta, esta norma estaría exigiendo que la clasificación se produjera antes del transcurso de los dos meses que, desde la entrada en vigor de la LERSAL, tiene el consorcio para adaptar el contenido de los contratos. A lo que seguiría que, tras la comunicación de dicha clasificación, se activaría el plazo máximo de tres meses para adaptar los estatutos, lo que entra en abierta contradicción con la solución, más flexible, que hemos propuesto antes,

70 Si bien, como ya se ha dicho, debe tenerse en cuenta que el anteproyecto de LRJSP prevé la derogación del art. 110 TRRL.

71 El conflicto también se produce con normas autonómicas, como el art. 81 de la LAULA, según el cual, "los órganos de gobierno estarán integrados por representantes de todas las entidades consorciadas, en la proporción estatutariamente establecida y sin que ninguno de ellos ostente mayoría absoluta".

72 Cfr. KONINCKX FRASQUET, A. (2014): 597. La aplicación de esta disposición a los consorcios también ha sido matizada en CASTILLO BLANCO, F. (2014): 902 y 903.

73 No vamos a entrar aquí en el análisis de lo dispuesto en el apartado 5 de esta Disposición adicional $12^{\mathrm{a}} \mathrm{LBRL}$, que va en la línea de lo previsto en la Ley 19/2013, de 9 de diciembre, de transparencia, acceso a la información pública y buen gobierno. Este precepto, que nos limitamos a reproducir aquí, establece lo siguiente: "Sin perjuicio de la publicidad legal a que estén obligadas, las entidades incluidas en el sector público local difundirán a través de su página web la composición de sus órganos de administración, gestión, dirección y control, incluyendo los datos y experiencia profesional de sus miembros. Las retribuciones que perciban los miembros de los citados órganos se recogerán anualmente en la memoria de actividades de la entidad."

74 En caso de producirse esta extinción, la propia Disposición adicional $12^{\mathrm{a}} \mathrm{LBRL}$, en su apartado 7, prevé que la misma no generará derecho alguno a integrarse en la estructura de la entidad local a la que se adscriba el consorcio, fuera de los sistemas ordinarios de acceso. 
de estar a los plazos generales de la Disposición transitoria 6 $6^{\mathrm{L}}$ LERSAL. Estamos ante un ejemplo más de la mala técnica de esta Ley, repleta de contradicciones y previsiones que inducen a confusión, por decirlo suavemente.

\section{NOVEDADES DE LA LEY 15/2014}

Si bien, el grueso de las modificaciones en el régimen jurídico de los consorcios han venido de la mano de la LERSAL a finales del año 2013, en una segunda fase, ya en septiembre de 2014, se han producido novedades significativas que también deben ser objeto de nuestro análisis. Estas novedades han tenido lugar mediante la Ley 15/2014, que se enmarca dentro de las medidas de reforma de las Administraciones Públicas que han seguido a la elaboración del llamado Informe CORA (Comisión para la reforma de las Administraciones Públicas) ${ }^{75}$. No siendo esta Ley, como es lógico, una norma que se dicte exclusivamente para introducir medidas de reforma de los consorcios administrativos, son estas últimas, contenidas fundamentalmente en sus arts. 12 a 15, las que vamos a examinar a continuación.

\section{Cuestiones preliminares}

La primera cuestión que hay que indicar sobre esta segunda fase de reforma del régimen jurídico de los consorcios es que, a diferencia de la realizada por la LERSAL, que obligaba a distinguir entre los preceptos aplicables a todos los consorcios y los que son solo para los consorcios locales, las modificaciones introducidas por la Ley 15/2014 son de aplicación a todos los consorcios administrativos. Con toda precisión, la Disposición final $4^{\text {a }}$ de esta Ley señala que, los preceptos sobre los consorcios recogidos en la misma tienen carácter básico y se dictan al amparo del art. 149.1.18 $\mathrm{CE}$, que establece la competencia estatal para determinar las bases del régimen jurídico de las Administraciones Públicas.

La segunda precisión que debe hacerse es que esta nueva regulación se diseña como provisoria, a expensas de una regulación futura del régimen de los consorcios, que se hará en la nueva Ley de Régimen Jurídico de las Administraciones Públicas, que vendrá a sustituir a la actual LRJPAC ${ }^{76}$. Así de claro lo dice el Preámbulo de la Ley, en su apartado III. Si bien, habrá que ver lo que finalmente sucede, a la vista de la experiencia de tantas regulaciones que, anunciándose como provisorias, han terminado finalmente por durar muchísimos años.

La tercera indicación que haremos es la relativa al objeto de esta nueva regulación de los consorcios, que es establecer un régimen jurídico básico que discipline el ejercicio del derecho de separación de los miembros del consorcio, así como su disolución. Es ésta una materia apenas desarrollada por el legislador autonómico, que cuando la ha abordado se ha limitado a dictar algunas reglas para los consorcios locales, reglas bastante someras que dejaban la auténtica regulación de los procedimientos a los estatutos ${ }^{77}$. No existiendo en cualquier caso, hasta ahora, un régimen estatal básico, que permitiera cubrir los supuestos en que ni la normativa autonómica ni los estatutos del consorcio hubieran establecido previsión alguna al respecto. No obstante, debe decirse que, como tendremos ocasión de ver, tampoco el Estado ha optado con la reforma por regular realmente los procedimientos.

Desde esta perspectiva, esta nueva regulación podría valorarse positivamente, en tanto la realidad haya evidenciado la dificultad de llevar a cabo la disolución de un consorcio, o la separación de uno de sus miembros, a falta de regulación específica ${ }^{78}$. Otra cosa sería el conflicto que podría producirse tras la aprobación de esta nueva normativa, en caso de que entre en contradicción con la legislación autonómica preexistente, o la valoración que nos pudiera merecer en cuanto ocupe un espacio que se entendía reservado al legislador autonómico. Si bien, entendemos que poco conflicto se va a producir, puesto que las nuevas normas dictadas por el Estado en la Ley 15/2014 son, en su mayoría, bastante escuetas, no entran realmente en la regulación de los procedimientos, y se centran en el cálculo y pago de las correspondientes cuotas de separación y liquidación, respetando en gran medida la regulación estatutaria.

75 El Informe CORA fue asumido por el Consejo de Ministros el 21 de junio de 2013.

76 Como ya se ha apuntado en páginas precedentes, está regulación se hará en la finalmente llamada LRJSP, de la que ya se conoce, por haber sido sometido a información pública, el texto del anteproyecto de ley.

77 Puede citarse, a modo de ejemplo y sin ánimo de ser exhaustivo, la regulación establecida en la LAULA (arts. 76, 77 y 82), en el Decreto 179/1995, de 13 de junio, por el que se aprueba el Reglamento de obras, actividades y servicios de los entes locales de Cataluña (arts. 323 y 324), y en la Ley 5/1997, de 22 de julio, reguladora de la Administración Local de Galicia (arts. 143 , 144 y 151.2).

78 Si bien se trata de un supuesto afectado también por otras circunstancias en las que ahora no es dable entrar, no podemos dejar de citar aquí el paradigmático caso de los consorcios UTEDLT (Unidades Territoriales de Empleo, Desarrollo Local y Tecnológico) en Andalucía, cuyo proceso de disolución, que tiene su génesis en la Ley 1/2011, de 17 de febrero, de reordenación del sector público de Andalucía, aún no ha terminado, estando aún pendiente de liquidación y extinción definitiva. Si se quiere saber más, puede verse el Informe de la Cámara de Cuentas de Andalucía de Fiscalización Horizontal de la gestión de las ayudas de la Junta de Andalucía a las Unidades Territoriales de Empleo, Desarrollo Local y Tecnológico (UTEDLT), ejercicios 2010 a 2012 (publicado en BOJA $n^{\circ} 45$ de 7 de marzo de 2014). 
La preocupación del legislador estatal por regular esta materia es plenamente coherente con las medidas previas adoptadas para los consorcios en la LERSAL, pero también con las restricciones presupuestarias que han puesto en jaque al sector público en los últimos años en la estricta aplicación de la LOEPSF. Se regula teniendo presente una realidad, la existencia de consorcios en proceso de disolución o de consorcios que se sabe que se disolverán en un futuro próximo, como consecuencia de la aplicación de estas medidas, además de entidades que decidirán salir de los consorcios de los que formen parte ${ }^{79}$. De lo que se trata en el fondo es de facilitar la implantación de esta solución, que se entiende repercutirá en un sector público más racional y sostenible, mediante la reducción del mismo, lo que pasa por la disolución de consorcios existentes, o la huida de las entidades consorciadas. Para el legislador es importante, como precisa en el Preámbulo de la Ley, "contar ya con estas normas", que permitirán "a cualquier Administración Pública poder ejercer su derecho de separación del consorcio cuando considere que sea la solución más adecuada para la sostenibilidad de las cuentas públicas y se den los requisitos legales para ello". "Con este nuevo régimen", se dice, "se mejora la sostenibilidad y eficiencia de los consorcios y la seguridad jurídica de sus miembros". Creemos que, con el texto transcrito, no cabe duda que la perspectiva es, como afirmábamos, puramente económica y presupuestaria, de cumplimiento y ajuste a la LOEPSF ${ }^{80}$.

En cuarto lugar, en conexión con lo anterior, debemos señalar que no se atiende en la reforma a otras cuestiones relativas al régimen jurídico de los consorcios, faltas de regulación en la LRJPAC, como es el procedimiento de creación de los mismos, o sus normas de funcionamiento u organización. Solo se regula la separación y disolución bajo un criterio de inmediatez, por atender a la preocupación inmediata existente, en los términos que ya hemos descrito. Pero ello no significa que el legislador estatal no se plantee una regulación de estas otras cuestiones en el futuro, que, de hecho, anuncia en el propio Preámbulo de la Ley, indicando que, "posteriormente, en la futura Ley de Régimen Jurídico de las Administraciones Públicas, se incluiría un régimen integral (creación, adscripción, funcionamiento, disolución) y básico referido a los consorcios, que derogaría esta regulación y lo previsto en la LERSAL" $"$.

Para finalizar, debe decirse que, según el art. 15 de la Ley 15/2014, la adaptación de los estatutos de los consorcios a estas nuevas reglas sobre el derecho de separación de sus miembros, y la disolución y liquidación del mismo, deberá producirse en el plazo de seis meses a contar desde la entrada en vigor de esta Ley, siendo así que la Ley entró en vigor el 18 de septiembre de 2014. Este nuevo plazo de adaptación, que se suma al que ya establecía la LERSAL para adaptarse a sus previsiones (Disposición transitoria $6^{\mathrm{a}}$ ), está siendo entendido en la práctica como una moratoria tácita de dicho plazo, que expiraba el 31 de diciembre de 2014, o el 1 de enero de 2015, según el caso. La dificultad de abrir un doble proceso de modificación de los estatutos del consorcio, uno para realizar las adaptaciones exigidas por la LERSAL y otro para las exigidas por la Ley 15/2014, y en dos tiempos distintos, ha llevado a tomar esta solución, más sensata y operativa.

\section{La separación de los miembros del consorcio: causas, procedimiento y efectos}

Las causas de separación de los miembros del consorcio se establecen en el art. 12.1 de la Ley 15/2014, aunque no se trata de un listado de causas tasadas al uso. Lo que hace la Ley es distinguir entre dos situaciones, que el consorcio esté o no sujeto a término de duración. Si el consorcio no está sujeto a término, no se precisa causa específica de separación, más allá de la voluntad de la entidad consorciada de salir del mismo, lo que podrá hacer en cualquier momento. Si el consorcio está sujeto a término de duración, la Ley condiciona la salida del consorcio antes de plazo, a que uno de sus miembros incumpla sus obligaciones estatutarias. El legislador destaca, con una referencia expresa, el incumplimiento de aquellas obligaciones que impidan cumplir con el fin para el que fue creado el consorcio, como es la obligación de realizar aportaciones al fondo patrimonial. Está claro que preocupa la sostenibilidad del consorcio. Si éste deja de ser sostenible, porque uno de sus miembros no cumpla con la obligación de sostenerlo en la parte que le corresponda, está legitimada la salida del mismo ${ }^{82}$.

79 Esta realidad ha sido convenientemente documentada en MARTíNEZ-ALONSO CAMPS, J.L. (2015): 18-20, quien, extrayendo la información de la Base de datos general de las entidades locales del Ministerio de Hacienda y Administraciones Públicas, da cuenta de que el número de consorcios del sector público local era de 1.020 a 31 de diciembre de 2013,952 a 22 de septiembre de 2014, y 932 a 9 de febrero de 2015.

80 En un sentido similar, en lo que hace a los fines de esta segunda fase de la reforma, puede verse la valoración que hace JIMÉNEZ ASENSIO, R. (2014): 2.

81 Este régimen integral y básico al que se refiere el Preámbulo de la Ley es el contenido en los artículos 93 a 102 del anteproyecto de LRJSP.

82 Ahora bien, la Ley 15/2014, en su Disposición adicional 6a da otra opción a la Administración estatal, para el caso de que alguna de las otras entidades consorciadas incumpla su obligación de realizar aportaciones al fondo patrimonial. La Ley permite a la Administración estatal, en cualquiera de sus personificaciones jurídico-públicas, que, siendo miembro de un consorcio, no se sienta obligada a efectuar la aportación al fondo patrimonial o la financiación a la que se haya comprometido para el ejercicio corriente, si alguno de los demás miembros del consorcio no hubiera realizado la totalidad de sus aportaciones dinerarias correspondientes a ejercicios anteriores a las que estén obligados.

REALA, n 3, enero-junio 2015, ISSN: 1989-8975 - DOI: http://dx.doi.org/10.24965/reala.v0i3.10239 
Por otra parte, la Ley añade una causa específica de separación para los consorcios locales, que solo puede entenderse en el contexto de la LERSAL. Se trata de permitir el ejercicio del derecho de separación de un municipio que deje de prestar un servicio que forme parte del objeto del consorcio. No tratándose de servicios obligatorios, si el municipio deja de prestar tal servicio, ya no estará interesado, como es lógico, en permanecer en el consorcio, con el coste económico que ello supone, por lo que estaría legitimada su salida del mismo. La Ley no es muy precisa, y ciertamente la utilización del término servicio quizás no sea especialmente afortunada, pero la referencia a la LERSAL, y la posibilidad de dejar de prestar el servicio, que no sería, por tanto, uno de los servicios municipales obligatorios del art. 26.1 LBRL, nos permite llegar a una conclusión. El legislador se está refiriendo a competencias municipales que, tras la LERSAL, dejen de serlo, como las competencias distintas de las propias o de las atribuidas por delegación, a las que se refiere el art. 7.4 LBRL, o algunas de las que salen de la órbita municipal y pasan a la Comunidad Autónoma, con la nueva redacción del art. 25.2 LBRL ${ }^{83}$.

El procedimiento de separación no es, realmente, objeto de regulación por la Ley 15/2014, que se limita a regular un requisito formal del ejercicio de este derecho (art. 12.2), así como la forma en que se debe proceder al cálculo y pago de la cuota de separación que le corresponda a quien lo ejerza (art. 13.2). Por tanto, el procedimiento de separación como tal, más allá de estas concretas reglas que poco tienen que ver con el mismo, seguirá siendo el establecido en los estatutos del consorcio, o en la legislación autonómica de desarrollo. Si la falta de regulación estatal de este procedimiento era un problema, está claro que la Ley 15/2014 no lo ha solucionado.

Ahora bien, el art. 15.3 de la Ley 15/2014 dispone la aplicación, como Derecho supletorio, en lo no previsto en los estatutos ni en esta Ley, de las disposiciones del Código Civil sobre la sociedad civil. Pese a la dicción de este precepto legal, si no se quieren vulnerar competencias autonómicas, habrá que entender que esta supletoriedad solo juega para los consorcios estatales, o que, tratándose de consorcios administrativos con regulación en la legislación autonómica, debe pasar antes también por la posible aplicación de la misma. Por otra parte, el Código Civil ya tenía en cualquier caso el carácter de Derecho común y supletorio (art. 4.3), por lo que la principal virtualidad de este artículo sería pronunciarse sobre los preceptos exactos del Código Civil que el Estado entiende que son de aplicación en esta materia, a falta de previsión específica.

Como veníamos diciendo, lo único que el art. 12.2 dispone es la exigencia de remitir al máximo órgano de gobierno del consorcio un escrito en el que se comunique la voluntad de ejercer el derecho a la separación. En este escrito, dice el precepto, deberá hacerse constar el incumplimiento que motive la separación, la formulación de requerimiento previo de cumplimiento al ente incumplidor y el transcurso del plazo otorgado para cumplir el requerimiento.

Varias cuestiones nos plantea este artículo. La primera qué deba entenderse por "máximo órgano de gobierno del consorcio". En nuestra opinión, se está refiriendo aquí la Ley al órgano plenario en el que están representados todos los miembros del consorcio, pues es al que sus estatutos suelen reservar las decisiones más trascendentes acerca de su existencia, como la separación de un miembro del mismo. La segunda cuestión que creemos que debemos apuntar, aún siendo obvia, es que, pese a que el precepto lo enuncia, en mala técnica, sin distinguir los supuestos, según nuestro criterio, el requisito formal de hacer constar el incumplimiento y el requerimiento previo al miembro incumplidor, no es para todos los casos. En buena lógica, este requisito solo será exigible cuando la separación se ejerza con fundamento en el incumplimiento de otro miembro del consorcio. Ya hemos dicho que era obvio, pero al no expresarse bien la Ley, hemos pensado que debíamos aclararlo. Hubiera sido tan fácil para el legislador como añadir al texto del precepto el inciso “en su caso”.

De forma sorprendente, este mismo legislador establece en el art. 13.1 que el ejercicio del derecho de separación produce la disolución automática del consorcio. Sorprende tan drástica solución que articula como solución a una crisis en el seno del consorcio, provocada por la separación de uno de sus miembros, la disolución automática de éste. Indudablemente, aquí no hay ya un prejuicio acerca del funcionamiento del consorcio, sino un intento de alcanzar de la forma más inmediata posible uno de los objetivos de esta reforma, la eliminación del consorcio, en cuanto redundaría en una reducción de los entes que forman parte del sector público instrumental.

Pese al automatismo de esta medida, la Ley deja abierta una puerta, y permite salvar la continuidad del consorcio, si los miembros que no han ejercido el derecho de separación, así lo acuerdan expresamente. Pero exigiendo como requisito que sigan permaneciendo en éste "al menos, dos Administraciones, o dos entidades u organismos públicos vinculados o dependientes de más de una Administración”. Lo que no se quiere es que se mantenga un consorcio participado por dos entidades instrumentales que, realmente, dependan de la misma Administración. Tampoco se contempla, por lo que debe considerarse excluida, la posibilidad de mantener un consorcio si las entidades que subsistan fueran una entidad pública y una entidad privada sin ánimo de lucro. En

83 Para conocer en profundidad este tema, puede verse el análisis que hemos hecho en TOSCANO GIL, F. (2014). 
todo caso, la Ley quiere que haya al menos dos entidades públicas. Finalmente, para el caso de que el ejercicio del derecho de separación no conlleve la disolución del consorcio, el art. 13.2 establece las reglas necesarias para calcular la cuota de separación, y proceder a su pago.

En lo que hace a lo primero, la Ley determina que ésta se calculará de acuerdo con la participación que le hubiera correspondido al que se separa del consorcio en el saldo resultante del patrimonio neto, de haber tenido lugar la liquidación, ajustándose al criterio de reparto establecido en los estatutos. A falta de previsión estatutaria, dice la Ley que se considerará cuota de separación la que le hubiera correspondido en la liquidación. En defecto de determinación de la cuota de liquidación se tendrán en cuenta, tanto el porcentaje de las aportaciones que haya efectuado quien ejerce el derecho de separación al fondo patrimonial del consorcio, como la financiación concedida cada año. Si el miembro del consorcio que se separa no hubiere realizado aportaciones por no estar obligado a ello, el criterio de reparto será la participación en los ingresos que, en su caso, hubiera recibido durante el tiempo que ha pertenecido al consorcio.

En lo que hace al pago de la cuota de separación, la Ley dispone que se acordará por el consorcio la forma y condiciones en que éste se hará efectivo, en el supuesto de que la cuota resulte positiva, así como la forma y condiciones del pago de la deuda que corresponda a quien se quiere separar si la cuota resultara negativa. La Ley realmente no dice nada, se limita a remitir esta cuestión a la decisión de las entidades consorciadas en el seno del consorcio.

Finalmente, distingue, en cuanto a la eficacia de la separación, según la cuota hubiera resultado positiva o negativa, siendo así que, en el primer caso, la efectiva separación del consorcio se produce con la mera determinación de la cuota, mientras que en el segundo es necesario pasar antes por el pago de la misma.

Para terminar con este apartado, debemos decir que la Ley también contempla, en el mismo art. 13.2, la necesidad de acordar la adscripción del consorcio a otra entidad pública, conforme a los criterios establecidos por la LRJPAC en su Disposición adicional 20 $0^{a}$, para el caso de que la entidad que se separe hubiera sido hasta entonces la Administración de adscripción del consorcio.

\section{La disolución del consorcio}

La regulación por la Ley 15/2014 de la liquidación del consorcio en su art.14 comienza apuntando lo que podría tomarse por una obviedad, que "la disolución del consorcio produce su liquidación y extinción". Una obviedad, como decimos, si no fuera porque deben de ser muchos los consorcios que, habiéndose disuelto, estén aún en fase de liquidación, y pendientes de su extinción. Disolución, liquidación y extinción son, pues, términos distintos, con significados distintos. Otra cosa es la valoración que nos pueda merecer el tenor de la expresión legal, como si su sola afirmación fuera a tener un efecto taumatúrgico sobre tantos consorcios haya pendientes de liquidación y extinción.

Vaya por delante que, salvo alguna cuestión específica, lo único que interesa al legislador en este precepto es arreglar el cálculo y pago de las correspondientes cuotas de liquidación. No se regula, por tanto, realmente, el procedimiento de disolución del consorcio, que, nuevamente, se deja a los estatutos y a la legislación autonómica de desarrollo. En este caso, disponiendo la aplicación supletoria, al régimen de liquidación, de “lo dispuesto en el Real Decreto Legislativo 1/2010, de 2 de julio, por el que se aprueba el Texto Refundido de la Ley de Sociedades de Capital” (art. 15.3 Ley 15/2014), remisión que debe leerse con las cautelas que ya hicimos en el epígrafe anterior.

Sí señala el art. 14.1 que, "en todo caso será causa de disolución que los fines estatutarios del consorcio hayan sido cumplidos". No nos parece mal esta disposición, que indica algo tan evidente como necesario, que el consorcio se extingue por el cumplimiento de sus fines, lo que es una exigencia de su naturaleza de entidad instrumental, y una medida de sentido común, que podrá evitar la pervivencia de consorcios que no desempeñan función alguna, auténticos muertos vivientes. Por lo demás, nada más sobre la disolución del consorcio se prevé en este artículo, todas son normas sobre su liquidación, como hemos dicho.

El máximo órgano de gobierno del consorcio, esto es, el órgano plenario, según ya hemos argumentado, al adoptar el acuerdo de disolución deberá nombrar un liquidador. De no lograrse un acuerdo en el seno del consorcio acerca de la persona más indicada para llevar a cabo esta función, el papel de liquidador corresponderá, por imperativo de la Ley (art. 14.2), al administrador del consorcio, expresión que entendemos podría comprender al gerente del mismo, aunque lo cierto es que el precepto no se expresa con toda la precisión que sería deseable.

Sigue diciendo la Ley, ahora en el art.14.3, que el liquidador calculará la cuota de liquidación, de conformidad con lo previsto en los estatutos. Si no estuviera previsto en éstos, se calculará de acuerdo con la participación que corresponda a cada miembro en el saldo resultante del patrimonio neto tras la liquidación, teniendo en cuenta 
que el criterio de reparto será el dispuesto en los estatutos. A falta de previsión estatutaria, se tendrán en cuenta tanto el porcentaje de las aportaciones que haya efectuado cada miembro del consorcio al fondo patrimonial del mismo, como la financiación concedida cada año. Si alguno de los miembros del consorcio no hubiere realizado aportaciones por no estar obligado a ello, el criterio de reparto será la participación en los ingresos que, en su caso, hubiera recibido durante el tiempo que ha permanecido en el consorcio.

Como se habrá observado, las normas sobre el cálculo de la cuota de liquidación son, básicamente, las mismas que las del cálculo de la cuota de separación, a las que ya nos referimos en el epígrafe anterior. Por lo que hace al pago de esta cuota, el art. 14.4 remite, igual que hacía con la de separación, al acuerdo del consorcio para determinar la forma y condiciones en que tendrá lugar, si la cuota hubiera sido positiva. Si bien, a diferencia del supuesto anterior, nada se dice para el caso de que fuera negativa.

Una última norma establece la Ley 15/2014 (art. 14.5) en el precepto dedicado a la liquidación del consorcio. Se contempla la posibilidad de que, las entidades consorciadas acuerden, con la mayoría que se establezca en los estatutos, o, a falta de previsión estatutaria, por unanimidad, la cesión global de activos y pasivos a otra entidad jurídicamente adecuada, con la finalidad de mantener la continuidad de la actividad y alcanzar los objetivos del consorcio que se liquida ${ }^{84}$.

\section{CONCLUSIONES}

La nueva regulación de los consorcios administrativos, establecida por la LERSAL y la Ley 15/2014, se caracteriza por un incremento de la heterorregulación de su régimen jurídico, que deja menos sitio a la autorregulación por las entidades consorciadas mediante sus estatutos, especialmente, la primera, en bastante menor medida, la segunda. En la medida en que esta heterorregulación se hace a través de normas estatales básicas, no solo se deja menos espacio a la autorregulación por las entidades consorciadas, sino también a la heterorregulación por las Comunidades Autónomas con competencias en la materia.

El nivel de heterorregulación desarrollado por el Estado en esta reforma es diverso, afectando especialmente al régimen de los consorcios participados por entidades locales, lo que no quiere decir que no afecte al régimen del resto de consorcios administrativos, pero menos si se compara con los primeros.

Esta nueva regulación contiene un núcleo importante de limitaciones y prohibiciones, que afectan a los consorcios ya existentes, pero también a los que se constituyan en el futuro, condicionando su mantenimiento, o su propia constitución, en detrimento de la potestad de autoorganización de las Administraciones Públicas que quieran utilizar el consorcio como técnica de cooperación.

Estas limitaciones obedecen exclusivamente a un enfoque económico-financiero o presupuestario. Se introducen para facilitar el control de los consorcios desde esta perspectiva, o porque redundarán en una disminución del gasto público. No se detecta una preocupación por solucionar otros problemas del consorcio. Así, la regulación que se hace del derecho de separación de sus miembros, o de su disolución, no responde a la existencia de dificultades reales detectadas en el pasado, sino que está hecha pensando exclusivamente en facilitar la salida de los miembros, o su disolución.

La flexibilidad de la institución consorcial, que ha sido una de sus señas de identidad, ha desaparecido, o, al menos, se ha visto bastante mermada con esta nueva regulación estatal básica. Esto va a influir decisivamente en la elección de nuestras Administraciones Públicas sobre cuál es el instrumento de cooperación interadministrativa más adecuado, en los casos en que sea necesario poner una de estas técnicas al servicio de un interés común. Sin duda, se sopesarán los nuevos inconvenientes de los consorcios, en cuya nueva configuración por el Estado ha pesado más su dimensión de entidad instrumental que su vertiente de técnica de cooperación interadministrativa.

Podría pensarse que, al mismo tiempo que se introducen todas estas limitaciones, la funcionalidad del consorcio se ha visto potenciada por el nuevo art. 26.2 LBRL introducido por la LERSAL, que prevé su utilización como fórmula de gestión compartida para la prestación de determinados servicios en los municipios con población inferior a 20.000 habitantes, bajo la coordinación de la Diputación Provincial. Pero hay que tener en cuenta que la utilización del consorcio en estos casos no está exenta de la aplicación de las importantes limitaciones que aquí hemos ido analizando, muy significativamente la que impide a los municipios durante el tiempo de vigencia de su plan económico-financiero o de su plan de ajuste, participar en la constitución de nuevos consorcios. Va a ser difícil, al menos hasta que la situación económica de nuestro país mejore, que dentro del ámbito territorial sujeto a la coordinación de la Diputación no haya municipios bajo un plan económico-financiero o de ajuste, que, por

84 Nos parece llamativo que esta última previsión no solo se haya incorporado también al texto del anteproyecto de LRJSP, lo que es lógico, sino que se destaque expresamente, entre tantas medidas, en la Exposición de Motivos de la misma. 
razón de la prohibición establecida en la Disposición adicional $9^{a}$ LBRL, no puedan participar en la constitución del consorcio provincial. Por esta razón, el consorcio no sería una buena solución en estos casos, no se nos alcanza qué economía de escala podría lograrse con el territorio fracturado.

Por estas, y por tantas otras razones que hemos ido dando a lo largo de este trabajo, la encrucijada en la que se encuentra el consorcio administrativo resulta esencial, puesto que va a determinar su supervivencia en el futuro. No pensamos que las Administraciones Públicas vayan a dejar de utilizar una figura tan consolidada como ésta, con tanta tradición en nuestra cultura institucional, pero sí creemos que, la menor flexibilidad de su régimen jurídico va a influir decisivamente sobre su uso, se va a utilizar mucho menos, disminuirá el número de consorcios existentes, y no se van a crear a la ligera.

\section{BIBLIOGRAFÍA}

BARRERO RODRÍGUEZ, C. (2002): "Los conceptos de mancomunidades y consorcios: necesidad de delimitación y diferenciaciones", Revista Andaluza de Administración Pública, nº 45.

CASTILLO BLANCO, F. (1991): "Los consorcios de entidades locales: análisis y valoración de la nueva legislación de régimen local”, Revista de Administración Pública, $\mathrm{n}^{\circ} 124$.

CASTILLO BLANCO, F. (2001): "Los consorcios administrativos: especial referencia a los consorcios de entidades locales en la legislación andaluza", Revista Andaluza de Administración Pública, nº 42.

CASTILLO BLANCO, F. (2014): "La nueva regulación de los consorcios públicos: interrogantes y respuestas sobre el régimen jurídico de su personal”, Revista Vasca de Administración Pública, n 99-100. Civitas.

COSCULLUela MONTANER, L. (2008): Manual de Derecho Administrativo. Tomo I, Cizur Menor,

ESCRIBANO COLLADO, P. (2002): "Los estatutos de las mancomunidades y consorcios locales: principios informadores y contenido legal (I)”, Revista de Estudios de la Administración Local, n 288.

FERREIRA FERNÁNDEZ, A.J. (2009): "Los consorcios del sector público autonómico: naturaleza y características”, Revista de Estudios de la Administración Local y Autonómica, $\mathrm{n}^{\circ} 310$.

GONZÁLEZ BUSTOS, M.A. (2014): "El nuevo reto de los consorcios”, en Quintana López, T. (dir.) y Casares Marcos, A.B. (coord.), La reforma del régimen local, Valencia, Tirant Lo Blanch.

JIMÉNEZ ASENSIO, R. (2014): “¿Réquiem por los consorcios? Notas sobre el Nuevo régimen jurídico de los consorcios tras la LERSAL", Blog www.estudiconsultoria.com, 7 de junio.

KONINCKX FRASQUET, A. (2014): "De nuevo sobre los consorcios", en Domingo Zaballos, M.J. (coord.), Reforma del Régimen Local: la Ley de Racionalización y Sostenibilidad de la Administración Local. Veintitrés estudios, Cizur Menor, Aranzadi.

LÓPEZ MENUDO, F. (1995): "Servicios municipales y gestión consorciada", en AA.VV., Jornadas de estudios sobre consorcios locales, Granada, CEMCI.

MARTíN MATEO, R. (1970): Los consorcios locales, Madrid, Instituto de Estudios de Administración Local.

MARTÍN MATEO, R. (1987): Entes locales complejos: mancomunidades, agrupaciones, consorcios, comarcas, áreas metropolitanas, Madrid, Trivium.

MARTÍNEZ LÓPEZ-MUÑIZ, J.L. (1974): Los consorcios en el Derecho español: (análisis de su naturaleza jurídica), Madrid, Instituto de Estudios de Administración Local.

MARTÍNEZ-ALONSO CAMPS, J.L. (2014): "El sector público local. Redimensionamiento y gestión de actividades y servicios públicos”, en Carrillo Donaire, J.A. y Navarro Rodríguez, P. (coord.), La reforma del régimen jurídico de la Administración local. El nuevo marco regulatorio a la luz de la Ley de racionalización y sostenibilidad de la Administración Local, Madrid, La Ley-Grupo Wolters Kluwer.

MARTÍNEZ-ALONSO CAMPS, J.L. (2015): "Novetats introduïdes en la Llei de bases de règim local: des dels requisits de constitució dels consorcis fins a la incidència del redimensionament del sector públic local", Galán Galán, A. (coord.), Jornada sobre l'aplicació de la reforma legal dels consorcis, http://eapc. gencat.cat/ca/detalls/Article/Jda_consorcis, Barcelona, Escola d'Administració Pública de Catalunya.

MEDINA GUERRERO, M. (2014): La reforma del régimen local, Valencia, Tirant Lo Blanch. 
MELLADO RUIZ, L. (2014): Génesis y realidad de la Ley 27/2013, de 27 de diciembre, de Racionalización y Sostenibilidad de la Administración Local: ¿una nueva reforma económica local?, Granada, CEMCI.

MONTOYA MARTÍN, E. (2012): "Reflexiones sobre el sector público instrumental en un contexto de crisis económica: la inaplazable hora de la racionalización”, en Casado Casado, L., Fuentes i Gasó, J.R., y Gifreu i Font, J. (coord.), Estructuras administrativas y racionalización del gasto público. Problemas actuales de la expropiación forzosa. La reforma de los entes locales en Italia en el contexto de la crisis económica, Madrid, INAP.

MONTOYA MARTÍN, E. (2014): “Medidas de redimensionamiento del sector público instrumental local antes y después de la Ley $27 / 2013$, de 27 de diciembre de racionalización y sostenibilidad de la Administración local”, en Revista General de Derecho Administrativo, n 36.

NIETO GARRIDO, E. (1997): El consorcio administrativo, Barcelona, Cedecs.

NIETO GARRIDO, E. (2001): “La naturaleza jurídica del consorcio administrativo a propósito de la Sentencia del Tribunal Supremo de 30 de abril de 1999", Revista de Estudios de la Administración Local, $\mathrm{n}^{\circ}$ 285 .

NIETO GARRIDO, E. (2014a): “La Ley de racionalización y sostenibilidad de la Administración local y los consorcios administrativos”, en Carrillo Donaire, J.A. y Navarro Rodríguez, P. (coord.), La reforma del régimen jurídico de la Administración local. El nuevo marco regulatorio a la luz de la Ley de racionalización y sostenibilidad de la Administración Local, Madrid, La Ley-Grupo Wolters Kluwer.

NIETO GARRIDO, E. (2014b): “La reforma de las entidades instrumentales por la Ley de racionalización y sostenibilidad de la administración local”, Revista Española de Derecho Administrativo, n 165.

REBOLLO PUIG, M. (1997): “Los consorcios entre entes locales como forma de cooperación”, en Font i LLovet, T. (dir.), Anuario del Gobierno Local 1997, Madrid, Diputación de Barcelona, IDP, Marcial Pons.

TOSCANO GIL, F. (2010): “La nueva regulación del consorcio local en la Ley de Autonomía local de Andalucía”, Revista de Estudios de la Administración local y Autonómica, n 313-314.

TOSCANO GIL, F. (2011a): "La definición del consorcio local como entidad local en la legislación autonómica", Cuadernos de Derecho Local, n 27.

TOSCANO GIL, F. (2011b): Los consorcios metropolitanos, Barcelona, Madrid, Fundación Democracia y Gobierno Local, IAAP.

TOSCANO GIL, F. (2012): “Título V. La cooperación territorial: entidades e instrumentos para la cooperación territorial. Mancomunidades, consorcios, convenios y redes de cooperación”, en Rivero Ysern, J.L. (dir.), Montoya Martín, E. y Fernández Ramos, S. (coord.), Derecho local de Andalucía: la Ley 5/2010, de 11 de Junio de Autonomía Local de Andalucía, Madrid, lustel.

TOSCANO GIL, F. (2013): “La reforma local y la intermunicipalidad”, en Feria Toribio, J.M. (coord.), Mancomunidades, consorcios, áreas metropolitanas y redes de municipios, Sevilla, CENTRA.

TOSCANO GIL, F. (2014): “El nuevo sistema de competencias municipales tras la Ley de racionalización y sostenibilidad de la administración local: competencias propias y competencias distintas de las propias y de las atribuidas por delegación”, Revista Española de Derecho Administrativo, nº 165.

VELASCO CABALLERO, F. (2014): "Títulos competenciales y garantía constitucional de autonomía local en la Ley de Racionalización y Sostenibilidad de la Administración Local”, en Santamaría Pastor, J.A. (coord.), La reforma del 2013 del régimen local español, Barcelona, Madrid, Fundación Democracia y Gobierno Local. 
